\title{
Biophysical and Computational Landscapes of Mycobacterial Pyrophosphatase: A Closer View of Drug Repurposing With Different Natural and Synthetic Compounds.
}

Shivangi Shivangi

CSIR Institute of Genomics \&amp; Integrative Biology

Laxman Meena ( $\square$ meena@igib.res.in )

CSIR-Institute of Genomics and Integrative Biology https://orcid.org/0000-0002-1356-496X

\section{Research Article}

Keywords: Mycobacterium tuberculosis, ppa, GTPase inhibitor, GTP, ITC

Posted Date: March 16th, 2021

DOl: https://doi.org/10.21203/rs.3.rs-295339/v1

License: (c) (i) This work is licensed under a Creative Commons Attribution 4.0 International License.

Read Full License 


\section{Abstract}

Mycobacterial pyrophosphatase (Mt-ppa) play essential role in bacterial in vitro and in vivo survival. This family of proteins reacts on pyrophosphates to release orthophosphates and protect bacteria from pyrophosphates toxicity. Rv3628 encodes pyrophosphate protein which is a type I pyrophosphate protein. This protein is engaged in hydrolysis of tri and diphosphates (majorly GTP, ATP and GDP) and its catalysis is metal ion dependent. Mt-ppa was showed efficient interaction with GTP molecule, whose Kd was $37.9 \mu \mathrm{M}, \Delta \mathrm{H}$ was $-11 \mathrm{Kcal} / \mathrm{mol}$ and $\Delta \mathrm{G}$ was $-6.06 \mathrm{Kcal} / \mathrm{mol}$. The protein was interacted with ATP family genes that resemble that it is participator in conversion of diphosphates moiety to the residual monophosphates. W102G, V150G, F44G, I119G, L93F, F3G, F122G, I108G, L32G, M82G, Y17G, L59G, V5G, V26G, I7G, W140D, W140G, W140A, F80G, W140S, L49G, L56G, 19G, V60G, V19G, V92G, L28G, L61G, Y126E and F123G are the top 30 mutation hits and Y126G, Y42G, R30G, E8G, K16G are top mutational hits in active site of Mt-ppa. Mt-ppa is temperature and $\mathrm{pH}$ sensitive as increasing temperature and $\mathrm{pH}$ decreases protein stability. It is also the receptor for several kinases that phosphorylate this protein at different Ser/Thr/Tyr sites. Virtual screening of 700 compounds from herbal ingredient targets (HITs) subset of zinc database give ZINC000003979028, ZINC000003870413, ZINC000003870412, ZINC000150338758, ZINC0000070450948, ZINC000150338754, ZINC000095098891, ZINC000000119985, ZINC000005085286 as the top target hits and Mac0182344 and NAV_2729 as the top GTPase inhibitor that can target and hinders Mt-ppa activity.

\section{Highlights}

- To establish better survival niche inside host, Mtb acquire different molecular strategies to tolerate stress.

- Inorganic pyrophosphate (PPi) is the product of essential processes of signaling pathways etc.

- Its accumulation leads to pyrophosphate (PPi) toxicity that may hinder several pathways of Mtb.

- GTPase inhibitor Mac0182344 and NAV_2729 showed largest binding affinity and may inhibits the reaction.

- Herbal Ingredient Targets (HITs) can be potential therapeutic for the treatment of disease.

\section{Introduction}

Mycobacterium tuberculosis ( $\mathrm{Mtb}$ ) is a pathogenic bacterium requires the machinery that involved coordinated gene expression to retort different condition applied by host immune system [1]. The cordial gene expression augments bacterial persistence and multiplication resulting in disease characteristic appearance. To establish better survival niche inside host, Mtb acquire different molecular strategies that involve different gene expressions such as metal acquition proteins, DNA repair proteins, $\mathrm{pH}$ maintenance, genes involved in toxic products removal and genes involved in thermotolerance etc. [2-3]. Inorganic pyrophosphate (PPi) is the catabolic byproduct of many essential processes like synthesis of macromolecules (DNA, RNA, proteins etc.) and signaling pathways etc. [4-5]. The hydrolysis of these PPi 
into inorganic phosphate $(\mathrm{Pi})$ is an essential process for cell viability as accumulation of PPi forced an inhibitory effect on PPi generating processes. This hydrolysis step is driven by inorganic pyrophosphatases (ppase) that carry out a thermodynamic reaction involving breakdown of PPi. Apart from this hydrolysis reaction, it was also reported that Ppase can also catalyze the reverse reaction of formation of ppi with single pi [6]. Ppase protein is found to be conserved among different species and is characterized as ubiquitous in nature. They are mentioned as essential proteins in Escherichia coli (E. coli), yeast Saccharomyces cerevisiae (S. cerevisiae) and Mycobacterium tuberculosis (Mtb) [7]. These PPases have been classified into four families i.e. class I, class II and class III which are cytoplasmic origin proteins and class IV is mainly integral membrane protein which is involved in $\mathrm{H}^{+} / \mathrm{Na}^{+}$ transportation [8-10]. PPases are characterized on the basis of their structure and organism in which they present. Class I and II are mainly present in archaebacteria, eubacteria and eukaryotes that make these families ubiquitous whereas class III PPases are described to present in some bacterial species, but these are not much explored [11-12]. The eubacterial PPases are organized as homohexamers of each subunit size ranges between 19-22kDa whereas eukaryotic PPases are homodimers with 32-34 kDa of each subunit size with a long N-terminal protrusion [13]. Class I PPases of prokaryotes and eukaryotes shows the conserved pattern in functional site with containing 13 highly conserved amino acid residues [14]. Magnesium $\left(\mathrm{Mg}^{2+}\right)$ is found to be essential for the catalytic activity of PPases of all categories. In Mtb and other bacteria, ppal is present and designated as essential for bacterial survival. In case of Mtb, it is even considered the target for the development of potentially anti-tuberculosis drug regimen. Previous reports had already delivered the biochemical and structural information about $E$. coli and S. cerevisiae ppa and crystallographic reports were also present for mycobacterial ppa (Mt-ppa) with PDB ID: 1WCF [15]. Class I Ppases from Mtb are differ from other species in comprising two histidine's in the active site and its constitutive expression which is not regulated by any environmental stimuli in in vitro growth experiments. The two His residues in the active site lowered the bacilli $\mathrm{pH}$ in comparison to other bacteria. In addition, His 21 and His 86 were also found to be engaged in ATP and PNP hydrolysis reaction using $\mathrm{Mg}^{2+}$ and $\mathrm{Mn}^{2+}$ as cofactors [16-18].

There are many reports which elaborated the mutational impact on protein structural and functional integrity. Mt-ppase catalysis is active site and mental ion dependent and therefore mutation at specific residues of active site can disrupt their intermolecular interactions and thus hamper the overall protein catalysis and bacterial survival. There are 12 residues that are present in the active site of Mt-ppa in complexed with ppa which are as D84, D89, K127, K133, R30, K16, Y42, E8, D57, D89, H86, H21, P55. However, active site residues differ in the presence of different metal ions [19]. This article glimpses the effect of mutation on these active site residues on overall protein structure and function.

Overall protein stability and integrity is essential aspect of its proper functioning and any type of improperness in its function can put a drastic impact on organism genotype, phenotype and over its metabolism. The second main part of this manuscript describes the effect of different compounds on Mtppa integrity and functioning. The interaction was checked by docking analysis that was performed among three grouped compounds: GTPase inhibitors, Herbal ingredients targets (HITs) [20] and 
Nucleotide Tri Phosphates (NTPs). The motive behind the docking with GTPase inhibitors is to find the probable compound that can evaluate and disrupt its enzymatic activity. Further virtual screening of Zinc database HITs was used to find the potent compound to target ppa protein of Mtb with lesser toxicity in humans. Therefore, this article presents the merged view of in vitro and in silico sides of Mt-ppa protein with mainly focusing on its interaction pattern that can help to deeply understand the biology of this protein.

\section{Materials And Methods}

\section{In vitro experiments}

\section{Protein expression and purification}

The Mt-ppa gene was amplified by PCR reaction and used M. tuberculosis $\mathrm{H}_{37} \mathrm{Rv}$ genomic DNA as template. The primers for the reaction were as Forward Primer:

5'<GAGGATCCGCGTGCAATTCGACGTGACCATCG >3' and Reverse Primer:

5'<GCTCGAGTCAGTGTGTACCGGCCTTGAAGCGC>3'. The forward primer carrying Bam H/ restriction site and reverse primer carrying $\mathrm{Xhol}$ site. The gene was amplified by PTC-200 Peltier thermal cycler using the following program: initial denaturation at $95^{\circ} \mathrm{C}$ for 4 minutes followed by 30 cycles of $94^{\circ} \mathrm{C}$ for 1 minute, $63^{\circ} \mathrm{C}$ for 1 minutes, and $72^{\circ} \mathrm{C}$ for 1.30 minutes with a final extension at $72^{\circ} \mathrm{C}$ for 7 minutes. Both Mt-ppa PCR product and pPRO-EX-HTc vector were restriction digested with Bam $\mathrm{HI}$ and $\mathrm{Xhol}$ to form compatible sticky ends. The size of both DNA and plasmid fragments were confirmed by agarose gel electrophoresis and consistent bands were purified from the agarose gel by Qiagen gel extraction kit as per manufacturer's protocol [21]. The sticky ends generated in vector and insert were then used for ligation which was done at $16^{\circ} \mathrm{C}$ for overnight. The ligation mixture was heat inactivated at $65^{\circ} \mathrm{C}$ and the transformed into chemically competent HIT DH5a cells. The colonies were screened; plasmid was isolated and confirmed by restriction digestion. The plasmid was then transformed into chemically competent BL-21 (DE3) strain for protein expression. Taq DNA polymerase used for PCR and T4 DNA Ligase used for cloning were purchased from New England BioLabs (NEB).

Transformants were inoculated in $5 \mathrm{ml}$ LB broth with $100 \mu \mathrm{g} / \mathrm{ml}$ ampicillin and incubated in an incubator shaker for overnight shaking at $200 \mathrm{rpm}, 37^{\circ} \mathrm{C}$. The protein was induced by Isopropyl- $\beta$-thiogalactoside (IPTG), which was added to the culture when $\mathrm{OD}_{600}$ reached 0.6-0.7 in around 2-2.30 hours and culture was induced for next 5-5.30 hours. Cells were harvested by centrifugation at 10,000 rpm for 20 minutes at $4^{\circ} \mathrm{C}$. Pellets were resuspended in $12 \mathrm{ml}$ sonication buffer $(50 \mathrm{mM}$ sodium phosphate buffer $\mathrm{pH} 8.0,300$ $\mathrm{mM} \mathrm{NaCl}, 1 \mathrm{mM}$ PMSF). Cells were lysed by sonication at $4^{\circ} \mathrm{C}$ for 5 minutes with an on and off cycle of 30 seconds till the lysate was clear. The sonicated cells were then centrifuged at 10,000 rpm for 30 minutes for removal of cell debris. The collected supernatant was then mixed with Ni-NTA resin (purchased for Qiagen) for 3 hours and then washed by washing buffer ( $50 \mathrm{mM}$ sodium phosphate buffer $\mathrm{pH} 6.0,300 \mathrm{mM} \mathrm{NaCl}, 10 \%$ glycerol, $10 \mathrm{mM}$ imidazole). The protein was eluted in elution buffer $(50 \mathrm{mM}$ 
sodium phosphate buffer $\mathrm{pH} 8.0,300 \mathrm{mM} \mathrm{NaCl}, 10 \%$ glycerol, $0.2 \mathrm{M}$ imidazole). Eluted fractions were then checked on $10 \%$ SDS PAGE for purity and quantified using Bradford assay [22].

\section{Dynamic Light Scattering}

Dynamic light scattering was used to visualize the oligomeric state of the protein. The experiment was performed at $25^{\circ} \mathrm{C}$ and the reaction was set up at $\mathrm{pH} 8.0 .0 .8 \mathrm{mg} / \mathrm{ml}$ protein concentration was used for the experiment which was made in buffer containing $50 \mathrm{mM}$ sodium phosphate buffer $\mathrm{pH} 8.0,300 \mathrm{mM}$ $\mathrm{NaCl}, 1 \mathrm{mM}$ PMSF. 1-cm path length cuvette was used with a volume capacity of $1 \mathrm{ml}$. A total of 20 runs were averaged with an equilibration time of 70 s. Zetasizer software (Ver. 6.20) analysis program was used for analyzing the histogram and the diameter of Mt-ppa protein was determined [23-24].

\section{Isothermal Titration Calorimetry}

The interaction of ppa with GTP was also confirmed by identifying the thermodynamic parameters of the interaction was checked by Isothermal titration calorimetry. All calorimetric reactions were performed on Malvern PEAQ ITC (Microcal, INC; Northampton, MA). All protein, ligand and buffer samples were filtered through $0.22 \mu$ filter and degassed thoroughly prior to the start of the experiment. The protein was diluted in buffer containing $50 \mathrm{mM}$ sodium phosphate buffer $\mathrm{pH} 8.0,300 \mathrm{mM} \mathrm{NaCl}, 1 \mathrm{mM}$ PMSF to make a final concentration of $5 \mu \mathrm{M}$ (in the cell) in a volume of $500 \mu \mathrm{l}$ and GTP was also diluted in the same buffer to a concentration of $500 \mu \mathrm{M}$ (in the syringe) in $80 \mu \mathrm{l}$. GTP was titrated into the protein with a total of 13 injections with the first injection being of $0.4 \mu \mathrm{l}$ and subsequent injections of $3 \mu \mathrm{l}$ each with a data interval of 180 seconds. The reaction was performed at $25^{\circ} \mathrm{C}$. Heat burst curves were obtained and the area under the curve was calculated using the Malvern inbuilt analysis program [25-26].

\section{In silico methods}

\section{Interaction pattern}

The crosstalk between proteins is an essential phenomenon for establishment of any biological pathway and thus this is also important for cell survival. STRING database server provides all necessary details regarding protein-protein functional association [27]. This server utilizes scoring matrix for evaluation that ranges from 0 to 1 . The value near to 1 represents strong interaction whereas the value near to 0 denotes weak interactions among proteins. On the similar pattern of analysis, STITCH server was used determine protein- compound interaction [28].

\section{B cell and T cell epitope prediction}

Evaluation of B-cell and T-cell epitopes is fundamental for some immunological, clinical and natural applications including diagnostics, disease control, improvement of immunizations and antibodies progression [29]. We have determined these epitopes by using BCpred and ABCpred computational techniques. By utilizing BCpred and ABCpred worker the epitope of B-cell and T-cells were anticipated 
individually. To anticipate Major histocompatibility complex (MHC) I and II restricting peptides HLApred worker was utilized [30].

\section{Prediction of subcellular localization}

The protein cell confinement was anticipated by LOC tree3 and TBpred server [23]. The prediction of protein sub-cell localization is a significant advancement toward clarifying protein work. The strategy yields a score that mirrors the unwavering quality of every function. The server includes the machine learning-based LocTree2 and improves over it through the addition of homology-based inference. The server acknowledges entries running from single protein sequence to whole proteomes. Another tool TBpred which is the SVM based technique for subcellular localization forecasting strategy for mycobacterial protein is likewise utilized for foreseeing four localization areas for example cytoplasmic, secretory, indispensable film and layer connected protein [31].

\section{Ligand binding site prediction}

Association of ligand with protein and the area or site of restricting encourages protein to work appropriately. Numerous bioinformatics servers were utilized to predict the coupling site like 3DLigandSite, ProBis, FINDSITE. These tools are layout-based strategies and LIGSITE and VICE were utilized as math-based techniques. Here we utilized a $\mathrm{COACH}$ server that gives clues regarding the site that binds to Mt-ppa. Sequence arrangement and 3D structure of target protein were used to produce reciprocal ligand restricting locales by utilizing two strategies for example TM-SITE and S-SITE which perceive ligand-binding format from the BioLip protein work information base [32]. ProBis web server recognizes the capable ligand interaction to the ppa protein structure. The structure of Mt-ppa protein binding locales was contrasted and non-repeating protein structure information. Then the ligands sought in the similar binding site are transposed to the Mt-ppa by rotation and translation of their atoms. At that point the basic binding amino acid residues between Mt-ppa and source protein from which ligands are rendered are recognized [33].

\section{Active site analysis and residues selection}

Protein sequence of Mt-ppa was analyzed by Mycobrowser server that provides genomic and proteomic sequence of all mycobacterial species. Mycobrowser is a convenient webserver and provide all necessary information related to mycobacteria. It also includes data for mycobacterial structure, function, orthologs and all information regarding drug development. The protein sequence was used for determination of GTPase and pyrophosphatase active site motif [34].

\section{Structure based mutation analysis}

\section{Site Directed Mutator}

Site directed mutator is an in-silico tool to determine substitution mutation impact on overall protein stability. This tool serves as an input system for PDB derived structure and gives output as Gibbs free 
energy ( $\Delta \Delta \mathrm{G}$ value) of stability change. $\Delta \Delta \mathrm{G}$ values of stabilizing mutation ranges in $\Delta \Delta \mathrm{G}>$ $2.5 \mathrm{kcal} / \mathrm{mol}$ and destabilizing mutations ranges in $\Delta \Delta \mathrm{G}<2.5 \mathrm{kcal} / \mathrm{mol}$ [35].

\section{DUET}

DUET webserver analyzes the effect of missense mutations. It uses the joint methodological pattern of mCSM and SDM in an optimized indicator machine called Support Vector Machine. mCSM be subject to on graph-based system and can identify not just effect of single point mutation but also clarify proteinprotein and protein-nucleic acid binding [36].

\section{DynaMut}

Proteins are important and dynamic molecule that intrinsically associates with molecular signals. Dynamut exemplifies the effect of mutations and depends upon protein static structure. This server apparatuses two distinct but modest tactics to estimate and visualize steadiness of protein by variety of conformations and valuation of the role of mutations on dynamicity and stability of protein resulting in change in vibrational entropy. It can evaluate protein dynamics by single point mutations and setting the cutoff value $\Delta \Delta G \geq 0$ for stabilizing and $\Delta \Delta G<0$ for destabilization of the protein. DynaMut apparatuses NMA over two assorted advances, Bio3D and ENCoM, that provides rapid and basic admittance to influential and insightful analysis of protein motions. Normal Mode Analysis (NMA) designs consonant movement to peddle a viable dynamic framework for mutation [37].

\section{Virtual screening of GTPase inhibitor, NTPs and ZINC natural compounds against Mt-ppa}

Molecular docking-based virtual screening of all compounds with $1 \mathrm{sxv}$ was performed to predict their binding affinity and detailed interactions. The docking was performed using InstaDock, a single click molecular docking tool that automizes the entire process of molecular docking-based virtual screening [38]. The binding affinities between the ligand and protein were calculated using the QuickVina-W [39] (Modified AutoDock Vina [38]) program which uses a hybrid scoring function (empirical + knowledgebased) in docking calculations and a blind search space for the ligand.

The $p K i$, the negative decimal logarithm of inhibition constant [40] was calculated from the $\Delta G$ parameter while using the following formula:

$\Delta G=\mathrm{RT}\left(\operatorname{Ln} K i_{\text {pred }}\right)$

$K i_{\text {pred }}=\mathrm{e}^{(\Delta \mathrm{G} / \mathrm{RT})}$

$\mathrm{p} K i=-\log \left(K i_{\text {pred }}\right)$

where $\Delta G$ is the binding affinity $\left(\mathrm{kcal} \mathrm{mol}^{-1}\right), \mathrm{R}$ (gas constant) is $1.98 \mathrm{cal}^{*}\left(\mathrm{~mol} \mathrm{~K}^{-1}, \mathrm{~T}\right.$ (room temperature) is 298.15 Kelvin, and $K i_{\text {pred }}$ is the predicted inhibitory constant.

Ligand efficiency (LE) is a commonly applied parameter for selecting favorable ligands by comparing the values of average binding energy per atom [41]. The following formula was applied to calculate LE: 
$\mathrm{LE}=-\Delta G / \mathrm{N}$

where LE is the ligand efficiency $\left(\mathrm{kcal} \mathrm{mol}^{-1}\right.$ non-H atom $\left.{ }^{-1}\right), \Delta G$ is binding affinity $\left(\mathrm{kcal} \mathrm{mol}^{-1}\right)$ and $\mathrm{N}$ is the number of non-hydrogen atoms in the ligand.

\section{Results}

\section{Purification of Mt-ppa protein}

The Mt-ppa gene was cloned into pPRO-EX-HTc using BamHI and Xho/restriction site in forward and reverse primer respectively. Mt-ppa was over expressed in the BL-21 (DE3) strain with an N terminal Histag. The protein was induced by adding $1 \mathrm{mM}$ IPTG after $\mathrm{OD}_{600} 0.8$ and induction was checked by SDS PAGE analysis. The protein was purified with $80 \%$ purity and purified band appear at $18 \mathrm{kDa}$. Purified Mtppa+His was concentrated and quantified by Bradford assay to a concentration of to $1 \mathrm{mg} / \mathrm{ml}$ (Figure 1a).

\subsubsection{Thermodynamic analysis of Mt-ppa and GTP interaction}

Isothermal calorimetry was used to determine the type of interaction and heat involved for optimum interaction between Mt-ppa and GTP. The data was analyzed by fitting the heat burst curve in one site binding model. The stoichiometry $(\mathrm{N})$ and dissociation constant $\left(\mathrm{K}_{\mathrm{d}}\right)$ of the interaction were 10 and $37.9 \pm 7 \mu \mathrm{M}$ (Figure $1 \mathrm{~b}$ ). The heat was released in the form of enthalpy change $(\Delta \mathrm{H})$ which is $-11 \pm 1.2 \mathrm{kcal} / \mathrm{mol}$. $\Delta \mathrm{G}$ was $-6.3 \mathrm{kcal} / \mathrm{mol}$ and $-\mathrm{T} \Delta \mathrm{S}$ was $-4.96 \mathrm{kcal} / \mathrm{mol}$ (Figure $1 \mathrm{c}$ ).

\section{Interaction analysis}

STRING and STITCH servers were used to detect the protein-protein and protein-chemical interaction. STRING showed the prominent interaction with ATP synthase family (atpA, atpB, atpC, atpD, atpE, atpF, atpG and atpH), galU, Ppk1 and ppk2. The scores for all interactive partners were 0.9 (Figure 2a). STITICH server showed the interaction with phosphate, pyrophosphate, fluoride, calcium ion, glycerol with scores as $0.991,0.965,0.954,0.954$ and 0.946 respectively. The scoring of all interactions showed a strong interaction between protein- protein and protein-compound (Figure 2b).

\section{Ligand-binding Prediction}

$\mathrm{COACH}$ server is a meta server-based approach that was used for prediction of ligand binding site in the protein. $\mathrm{COACH}$ server works on two mechanisms known as TM-site and S- site that recognized ligand binding template from the BioLip database. The server found the top ligand that bind to the ppa were sulphate ion, phosphate ion, potassium ion, calcium ion and Manganese ion. The topmost confidence scores (C score) were 0.39 and 0.33 for sulphate and phosphate ion respectively. The consensus residues where sulphate ion binds are 16, 30, 84, 126 and 127 and where phosphate ion binds are 16, 30, 42, 57, $84,89,91,126$ and 127 . The TM site prediction was also cleared the binding of the protein with phosphate, sulphate and magnesium ions with $C$ score of $0.29,0.28$ and 0.26 respectively. The $S$ site results also found the interaction of manganese, phosphate and sulphate ions with $\mathrm{C}$ score $0.33,0.24$ 
and 0.20 respectively. In the COFACTOR outcome, the TM score were $0.970,0.969$ and 0.968 for calcium, manganese and phosphate ions respectively.

\section{Mutational analysis}

The impact of point mutations on the action and ability of Mt-ppa was assessed by utilizing sequencebased changes. The mutations were done utilizing EASE-MM, PROVEAN, l-Mutant and DynaMut servers. It is now a well-established actuality that point mutations are the significant aspect for certain diseases because of their affectability in affecting protein structure and function. Considering energy change in thermodynamics, a protein can stay stable which is in the folded state, or it is in the unfolded state that is also known as the unstable state of the protein. The distinction of energy between folded and unfolded states can be determined by Gibbs free energy $\Delta \mathrm{G}=\mathrm{Gu}-\mathrm{Gf}$, where $\mathrm{Gu}$ and $\mathrm{Gf}$ are without gibbs energy of unfolded and folded states separately. Another method used to measure change in Gibbs free energy of mutated and wild type protein is appeared by $\Delta \Delta \mathrm{G}$ where, $\Delta \Delta \mathrm{G}=\Delta \mathrm{Gm}-\Delta \mathrm{Gw}(\Delta \mathrm{Gm}=\mathrm{Gibbs}$ free energy of freak and $\Delta \mathrm{GW}=$ Gibbs free energy of wild kind protein).

On the basis of EASE-MM result which requires protein sequence information gives possibility of effect of mutations on each residue by changing into every other residue. The server gives top 30 mutations with highest destability. W102G, V150G, F44G, I119G, L93F, F3G, F122G, I108G, L32G, M82G, Y17G, L59G, V5G, V26G, 17G, W140D, W140G, W140A, F80G, W140S, L49G, L56G, I9G, V60G, V19G, V92G, L28G, L61G, $\mathrm{Y} 126 \mathrm{E}$ and $\mathrm{F} 123 \mathrm{G}$ are the top 30 hits by EASE-MM server by setting a cutoff $\Delta \Delta \mathrm{G}$ value of -4.0 (Table 1). In addition to the above-mentioned mutational hits, mutations were also carried out on active site residues. As Mt-ppa is a pyrophosphatase and carried out its work based on active site configuration, therefore mutations on the active side residues must be checked. There are 5 residues that are present in the active site as Y126G, Y42G, R30G, E8G and K16G (Table 2). Mutations at all active site residues showed a destabilized effect with the highest destabilizing effect of Y126G.

All mutational hits resulted from EASE-MM server were also checked by PROVEAN server that proved a mutation as deleterious or non-deleterious. The PROVEAN resulted in highest destabilized mutations of ppa i.e. W140D, W140A, W140S, W140G, Y17G, F122G, F123G and Y126E (Table 1). Mutations on active site residues Y126G, Y42G, R30G, E8G and K16G were also showed a destabilized effect with the highest destability at Y126G (Table 2).

Similarly, all 30 mutational hits were also checked by I-MUTANT 3.0 server and the result outcome showed that L28G, L32G, I7G, V26G, L93F, I119G, F122G, I108G, L59G, F80G, I9G and V19G (Table 1). Active site residue mutation showed destability at all point changes with the highest destability at K16G (Table 2).

Stress based mutation analysis was done by changing the $\mathrm{pH}$ and temperature from the optimum range to see if protein would attain stability or destability in different conditions. Increasing temperature from $4^{0} \mathrm{C}$ to $60^{\circ} \mathrm{C}$ (Table 3 ) showed a decrease in destability and increasing pH from 3 to 13 (Table 4) also showed a decrease in stability till pH 7 and slightly increase in stability after pH 7 to 13 . 


\section{Phosphorylation site prediction}

Protein phosphorylation controls an enormous assortment of biological processes in every living cell. In pathogenic microorganisms, the investigation of serine, threonine, and tyrosine (Ser/Thr/Tyr) phosphorylation has revealed insight into the course of infectious diseases, from adherence to have cells to microbial pathogenesis, replication, and ingenuity. Mass spectrometry (MS)-based phosphoproteomics has given worldwide guides of Ser/Thr/Tyr phosphor sites in bacterial microorganisms. The NetPhos3.1 server predicts serine, threonine or tyrosine phosphorylation positions in eukaryotic proteins utilizing outfits of neural organizations. Both conventional and kinase explicit predictions are performed. The initial region shows the name and length of the sequence followed by the amino acid sequence. At that point follows a task field depicting the anticipated class for every residue. If the residue is predicted NOT to be phosphorylated, either because the score is below the threshold or because the residue is not Ser/Thr/Tyr, that position is marked by a dot ('.'). Residues having a prediction score above the threshold are indicated by 'S', 'T' or ' $Y$ ', respectively (Table 5).

\section{The Epitopic recognition}

B cell epitope prediction was done by BCpred server which detects the amino acid chain of length 7-10 amino acids that are indulged in epitope like function. In BCpred there were 4 epitopes were found of length 20 amino acids at different positions. The epitopes were as AADWVDRAEAEAEVQRSVER at position 137 with score 0.996, EHGGDDKVLCVPAGDPRWDH at position 85 with score 0.99 , DVTIEIPKGQRNKYEVDHET at position 4 with score 0.921 and TPMAYPTDTGFIEDTLGDDG at position 34 with score 0.891. Another tool known as ABCpred was also used to the same information. The predicted $B$ cell epitopes are ranked according to their score obtained by trained recurrent neural network.

Higher score of the peptide means the higher probability to be as epitope. The threshold value was set at 0.51 and epitope length of 16 amino acids. The top four epitopes were FRMVDEHGGDDKVLCV, GVLVAARPVGMFRMVD, DVTIEIPKGQRNKYEV and FFVHYKDLEPGKFVKA at position 80, 69, 4 and 122 and with score $0.93,0.90,0.88$ and 0.88 respectively. HLA pred was used determine T cell epitope in combination with MHC-II molecule. The top ten epitopic regions were DLEPGKFVK, FELDAIKHF, FRMVDEHGG, GKFVKAADW, IKHFFVHYK, LLPQPVFPG, LPQPVFPGV, LVAARPVGM, LVLLPQPVF and LVLLPQPVF. A list os top epitopes were given in Table 6.

\section{Screening of compounds against Mt-ppa (1wcf)}

\section{Screening of ZINC herbal compound database}

Mt-ppa is an essential gene for in vitro and in vivo survival of Mycobacterium tuberculosis. Mt-ppa also provides advanced endurance mechanisms to the bacterium. Virtual screening was performed using docking to select the potent natural and synthetic inhibitor. We had used subset of Zinc database library known as Herbal ingredients targets (HITs) to select the herbal ingredient compound. Screening was performed by targeting the residues of active site and the results were generated. Among the 750 compounds from Zinc database of herbal ingredients, all compounds were successfully and Compound 
ZINC000003780340 showed the highest binding energy, which is followed by compound ZINC000003979028, ZINC000003870413, ZINC000003870412, ZINC000150338758, ZINC0000070450948, ZINC000150338754, ZINC000095098891, ZINC000000119985, ZINC000005085286 (Table 7).

\section{Screening of GTPase inhibitor}

GTPase inhibitors inhibit the GTPase activity of a protein and thus may hinders the metabolism of the bacterium. Total 16 inhibitors were used in the study were Mac0182344, NAV_2729, Br_GTP, ML141, Rhosin_HCl, NSC_23766, CID_1067700, ITX3, EHT1864, Berberine, Salirasib, Mac0174809, Mac0182099, CCG_50014, Nexinhib20, Mac0080023. The highest binding affinity was seen in Mac0182344 and NAV_2729. Mac0174809 and Mac0080023 are the synthetic molecules and structural analogues whereas the other two compounds namely Mac0182099 and Mac0182344 are the natural product (Table 7).

\section{Docking of NTPs with Mt-ppa}

Molecular docking was performed to check the binding of Mt-ppa with nucleotide tri and diphosphates. In the docking experiment, we found that Mt-ppa has the maximum binding affinity for Guanosine Di Phosphate (GDP) which is followed by UDP, GTP, ATP, ADP, CDP, CTP and UTP. The outcome of docking analysis showed that Mt-ppa having higher affinity for diphosphates in comparison to tri phosphates (Table 7).

\section{Discussion}

Tuberculosis is one of the major challenges among infectious diseases which has to be tackled for a proper production rate of a nation and whole world [41]. This disease majorly affects the under developing countries the most and this is due to various factors including, poverty, malnutrition, lack of knowledge, lack of education, improper vaccination [42]. The disease becomes more challenging with a coinfection like in case of diabetes, HIV-AIDS and most recent Covid-19 [43]. Therefore, deriving the proper medication against this malady is a primary need. This article is an attempt in the direction to deliver a more understanding view of Mycobacterium tuberculosis virulence and survival strategy [44-45]. Soluble inorganic pyrophosphatases (ppa) are essential proteins in Mycobacterium tuberculosis survival and depend on metal cofactor for their proper functioning in converting pyrophosphate to orthophosphate. This conversion is needy step in many biochemical reactions that yield pyrophosphate as a byproduct. Therefore, its regulation is also an important step for proper Mycobacterium tuberculosis metabolism and also this protein can utilize for targeting the metabolism of this pathogen. $\mathrm{Mg}^{2+}$ was found to be essential for the catalytic activity of ppa protein and in the absence of the $\mathrm{Mg}^{2+}$, there was loss of activity [46]. The structure of Mt-ppa was retrieved from PDB whose PDB ID is 1WCF and 1SXV. The comparison between these structures was done by overlapping of proteins (Figure 3). Active site residues were determined by CASTp server (Figure 4). Previous reports also established its role in NTPS 
hydrolysis. Therefore, this article represents the essential highlights of Mt-ppa protein which has to be noted to target this protein. This protein was found to be interacted with ATP synthase family proteins and its regulatory partner ptpA with high affinity scores. Those proteins are atpA, atpB, atpC, atpD, atpE, atpF, atpG and atpH. Atp family proteins are the essential molecule for Mycobacterium metabolism and its survival. The interaction of Mt-ppa with these proteins signifies their coordinated role in proper Mycobacterium functioning. The pyrophosphate released from in any step of the atp synthase reaction was converted into orthophosphate by Mt-ppa so prevent bacteria from pyrophosphate cytotoxicity. Therefore, targeting this gene leads to automatically target the atp gene family (Figure 2). The epitopic recognition was done by BCpred server that determined 4 epitopes at different positions and $\mathrm{T}$ cell epitope prediction was done by HLApred server [47]. The protein showed strong binding with different ligand partner for e.g. Mt-ppa has strong binding affinity for ions such as $\mathrm{SO}_{4}{ }^{2-}, \mathrm{PO}_{4}{ }^{3-}, \mathrm{K}^{+}, \mathrm{Ca}^{2+}$ and $\mathrm{Mn}^{+}$. The binding of different ions resembles the protein dependability over these metal ions and Mt-ppa might utilize these metals as its cofactor for pyrophosphatase activity [48]. Further we found that the protein gets phosphorylated at different positions at serine, threonine and tyrosine by different kinases. These phosphorylations might depict its transformed state which may be requiring for its activation (Table 5) [49]. Further mutational analysis revealed several mutational hits which will be required for targeting the essential points of this gene. By mutating those residues, the protein goes into highly destabilized state. Those hits are as W102G, V150G, F44G, I119G, L93F, F3G, F122G, I108G, L32G, M82G, Y17G, L59G, V5G, V26G, 17G, W140D, W140G, W140A, F80G, W140S, L49G, L56G, 19G, V60G, V19G, V92G, L28G, L61G, Y126E and F123G (Table 1). the active site of Mt-ppa comprises of 5 residues namely Y126G, Y42G, R30G, E8G, K16G (Table 2) and mutations at all 5 points and majorly at $Y 42$ cause a large decrease in protein stability due to drastic disruption of interatomic interactions (Figure 5) [50]. Further on checking and verifying these mutations by different servers (PROVEAN and I Mutant 3.0), the same pattern of stability decease was found. Mutual effect of mutations in Mt-ppa gene might be used for targeting this protein synthesis and functioning. Improper synthesis and function thus lead to accumulation of pyrophosphatases in Mycobacterium cytoplasm which may leads to cause pyrophosphate cytotoxicity. Docking analysis showed that Mt-ppa is more preserved for diphosphate nucleotides in comparison to triphosphate nucleotides (Figure 6).

Virtual screening and docking analysis showed that GTPase inhibitors also reacted with ppa with highest affinity showed by Mac0182344, NAV_2729, Br-GTP and ML-141 (Figure 7). Mac0182344 is a natural compound which also showed the inhibitory effect on $M$. tuberculosis engA which is a universally conserved GTPase protein. The minimum inhibitory concentration that kills $50 \%$ of total bacteria was 4.6 $\mu \mathrm{M}$ for MAC-0182344. NAV_2729 is an ARF6 inhibitor with IC ${ }_{50}$ value of $1.0 \mu \mathrm{M}$ and it binds at the GEF binding area and does not overlap with the nucleotide binding pocket of ARF6. The complex of inhibitor and ARF6 was stabled by formation of hydrogen bonds at Lys58 residue and inhibitor carbonyl group and $\mathbb{B}$-amino group [51]. The major contributors to the inhibitor-binding energy are Phe47, Trp62, Trp74, and Tyr77. Virtual screening with herbal ingredients targets showed ZINC000003780340, ZINC000003979028, ZINC000003870413, ZINC000003870412, ZINC000150338758, ZINC0000070450948, ZINC000150338754, ZINC000095098891, ZINC000000119985,

Page $12 / 33$ 
ZINC000005085286 as the top ten hits that target ppa protein with highest binding energy (Figure 8). The Lipinski rule of 5 was applied on these compounds to confirm their effectiveness as drugs (Table 8). The properties of these compounds were searched by Pass online (way2drug) server that was used for finding involvement of protein in different biological activity, including pharmacological effects, mechanisms of action, toxic and adverse effects, interaction with metabolic enzymes and transporters, influence on gene expression, etc. the top results were in Table 9 where $\mathrm{Pa}$ and Pi refers to probability being active and inactive respectively. Absorption and toxicity prediction were also done by SWISS-ADME and ADME-SAR which showed that absorbance of ZINC000000119985 was high and there was compound involved as blood brain barrier and all are non-carcinogens (Table 10). These compounds can be used as potential natural targets to conquer Mt-ppa protein functioning and thus halt Mtb metabolism and its survival. The docking analysis of Mt-ppa with different nucleotides showed that Mt-ppa also binds with other nucleotides and greatly with the diphosphates.

This article thus glimpses the essential versions of Mt-ppa targeting molecule and mechanism to halt its functioning completely. Bacterial PPiases are important enzymes and, therefore, are probable targets for inhibition by small molecules. Identification of such inhibitors should be permitted by advancement of assays willing to high-throughput screening (HTS).

\section{Conclusions}

This manuscript describes the mycobacterial pyrophosphatases functioning, interaction and identifies its potential inhibitors. Due to the expanding nature of this disease, it becomes necessary to think of a solution to get rid from this. Although there has been continuous research of era was done over this but the proper cure or vaccine or solution is still a topic of debate. Therefore, in this article we attempt to deliver information to target ppa protein which is essential protein mycobacterial in vitro and in vivo survival $[52,53,54]$. This article also identifies the potential hotspots on which mutation causes the large decrease in protein stability. The mutations were done by focusing the whole gene and the active site. All mutations showed decrease in protein stability. Further the effect of natural compounds and GTPase inhibitors were checked and both groups showed high binding affinity for ppa protein. The top binding partner were Mac0182344 and NAV_2729 from GTPase inhibitors and ZINC000003780340,

ZINC000003979028, ZINC000003870413, ZINC000003870412, ZINC000150338758,

ZINC0000070450948, ZINC000150338754, ZINC000095098891, ZINC000000119985, ZINC000005085286 from natural compounds. These outcomes thus fix a roadmap to discover potential target for mycobacterial pyrophosphatases.

\section{Abbreviations}

Tuberculosis (TB); Mycobacterium tuberculosis $\mathrm{H}_{37} \mathrm{Rv}$ (Mtb); Multidrug-Resistant TB (MDR-TB); Guanosine triphosphatases (GTPases); GTP-binding proteins (G-proteins); Protein Data Bank (PDB); Real Biotech Corporation (RBC); Luria Bertani agar (LB agar); Luria Bertani broth (LB broth); Isopropyl $\beta$ thiogalactoside (IPTG); Ethylene Di amine Tetra Acetate (EDTA); Phenylmethylsulphonyl Fluoride (PMSF); 
Sodium Dodecyl Sulphate Polyacrylamide Gel Electrophoresis (SDS PAGE); Guanine Nucleotide Exchange Factors (GEF); GTPases activating Proteins (GAP); Guanosine Di Phosphate (GDP); Polymerase Chain Reaction (PCR); Isothermal Calorimetry (ITC); Uridine Di Phosphate (UDP); Cytidine Di Phosphate (CDP); Adenosine Di Phosphate (ADP); Adenosine Tri Phosphate (ATP); Cytidine Tri Phosphate (CTP); Pyrophosphatase (ppa); Mycobacterial Pyrophosphatase (Mt-ppa); Normal Mode Analysis (NMA); Herbal ingredients targets (HITs)

\section{Declarations}

\section{Acknowledgement}

The authors acknowledge financial support from the Department of Science and Technology-SERB, Council of Scientific and Industrial Research-Institute of Genomics and Integrative Biology under the research project GAP0145 (SERB-DST Grant no: EEQ/2016/000514).

Funding: The work is supported by Department of Science and Technology-SERB, Council of Scientific and Industrial Research-Institute of Genomics and Integrative Biology under the research project GAP0145 (SERB-DST Grant no: EEQ/2016/000514).

Conflict of Interest: The authors declare no conflict of interest.

Availability of Data and materials: Authors agreed for the availability of data to ensure data transparency norms.

Code availability: Not applicable

\section{Author contribution:}

Shivangi: Conceptualize and design the study, did the experiments and write the manuscript,

Dr. Laxman S. Meena: Handles all corresponding activity, design the design study idea and experiments, help in write the manuscript and correctness.

Ethics Approval: Not applicable

Consent to participate: The author agrees for participation.

Consent for publication: The author agrees for all terms and conditions.

\section{References}

1. Triccas, J. A., \& Gicquel, B. (2001) Analysis of stress- and host cell-induced expression of the Mycobacterium tuberculosis inorganic pyrophosphatase. BMC microbiology 1, 3. https://doi.org/10.1186/1471-2180-1-3. 
2. Heithoff, D. M., Conner, C. P., \& Mahan, M. J. (1997). Dissecting the biology of a pathogen during infection. Trends in microbiology, 5(12), 509-513. https://doi.org/10.1016/S0966-842X(97)01153-0

3. Triccas, J. A., \& Gicquel, B. (2000). Life on the inside: probing mycobacterium tuberculosis gene expression during infection. Immunology and cell biology, 78(4), 311-317. https://doi.org/10.1046/j.1440-1711.2000.00934.x

4. Kornberg, A. (1962). Horizons in Biochemistry, edited by H. Kasha \& B. Pullman, pp. 251-264. New York: Academic Press.

5. De Meis L. (1984). Pyrophosphate of high and low energy. Contributions of $\mathrm{pH}, \mathrm{Ca}^{2+}, \mathrm{Mg}^{2+}$, and water to free energy of hydrolysis. The Journal of biological chemistry, 259(10), 6090-6097.

6. Baykov, A. A., Shestakov, A. S., Kasho, V. N., Vener, A. V., \& Ivanov, A. H. (1990). Kinetics and thermodynamics of catalysis by the inorganic pyrophosphatase of Escherichia coli in both directions. European journal of biochemistry, 194(3), 879-887. https://doi.org/10.1111/j.14321033.1990.tb19482.x

7. Chen, J., Brevet, A., Fromant, M., Lévêque, F., Schmitter, J. M., Blanquet, S., \& Plateau, P. (1990). Pyrophosphatase is essential for growth of Escherichia coli. Journal of bacteriology, 172(10), 56865689. https://doi.org/10.1128/jb.172.10.5686-5689.1990

8. Gajadeera, C. S., Zhang, X., Wei, Y., \& Tsodikov, O. V. (2015). Structure of inorganic pyrophosphatase from Staphylococcus aureus reveals conformational flexibility of the active site. Journal of structural biology, 189(2), 81-86. https:// doi.org/10.1016/j.jsb.2014.12.003

9. Gajadeera, C. S., Zhang, X., Wei, Y., \& Tsodikov, O. V. (2015). Structure of inorganic pyrophosphatase from Staphylococcus aureus reveals conformational flexibility of the active site. Journal of structural biology, 189(2), 81-86. https://doi.org/10.1016/j.jsb.2014.12.003

10. Kajander, T., Kellosalo, J., \& Goldman, A. (2013). Inorganic pyrophosphatases: one substrate, three mechanisms. FEBS letters, 587(13), 1863-1869. https://doi.org/10.1016/j.febslet.2013.05.003

11. Merckel, M. C., Fabrichniy, I. P., Salminen, A., Kalkkinen, N., Baykov, A. A., Lahti, R., \& Goldman, A. (2001). Crystal structure of Streptococcus mutans pyrophosphatase: a new fold for an old mechanism. Structure (London, England : 1993), 9(4), 289-297. https://doi.org/10.1016/s09692126(01)00587-1

12. Rantanen, M. K., Lehtiö, L., Rajagopal, L., Rubens, C. E., \& Goldman, A. (2007). Structure of the Streptococcus agalactiae family II inorganic pyrophosphatase at $2.80 \mathrm{~A}$ resolution. Acta crystallographica. Section D, Biological crystallography, 63(Pt 6), 738-743. https://doi.org/10.1107/S0907444907019695

13. Bennouna, J., Sastre, J., Arnold, D., Österlund, P., Greil, R., Van Cutsem, E., von Moos, R., Viéitez, J. M., Bouché, O., Borg, C., Steffens, C. C., Alonso-Orduña, V., Schlichting, C., Reyes-Rivera, I., Bendahmane, B., André, T., Kubicka, S., \& ML18147 Study Investigators (2013). Continuation of bevacizumab after first progression in metastatic colorectal cancer (ML18147): a randomised phase 3 trial. The Lancet. Oncology, 14(1), 29-37. https://doi.org/10.1016/S1470-2045(12)70477-1 
14. Sivula, T., Salminen, A., Parfenyev, A. N., Pohjanjoki, P., Goldman, A., Cooperman, B. S., Baykov, A. A., \& Lahti, R. (1999). Evolutionary aspects of inorganic pyrophosphatase. FEBS letters, 454(1-2), 75-80. https://doi.org/10.1016/s0014-5793(99)00779-6

15. Benini, S., \& Wilson, K. (2011). Structure of the Mycobacterium tuberculosis soluble inorganic pyrophosphatase Rv3628 at pH 7.0. Acta crystallographica. Section F, Structural biology and crystallization communications, 67(Pt 8), 866-870. https://doi.org/10.1107/S1744309111023323

16. Tammenkoski, M., Benini, S., Magretova, N. N., Baykov, A. A., \& Lahti, R. (2005). An unusual, Hisdependent family I pyrophosphatase from Mycobacterium tuberculosis. The Journal of biological chemistry, 280(51), 41819-41826. https://doi.org/10.1074/jbc.M509489200

17. Rodina, E. V., Vainonen, L. P., Vorobyeva, N. N., Kurilova, S. A., Sitnik, T. S., \& Nazarova, T. I. (2008). Metal cofactors play a dual role in Mycobacterium tuberculosis inorganic pyrophosphatase. Biokhimiia, 73(8), 897-905. https://doi.org/10.1134/s0006297908080075

18. Triccas, J. A., Britton, W. J., \& Gicquel, B. (2001). Isolation of strong expression signals of Mycobacterium tuberculosis. Microbiology (Reading, England), 147(Pt 5), 1253-1258. https://doi.org/10.1099/00221287-147-5-1253

19. Pratt, A. C., Dewage, S. W., Pang, A. H., Biswas, T., Barnard-Britson, S., Cisneros, G. A., \& Tsodikov, O. V. (2015). Structural and computational dissection of the catalytic mechanism of the inorganic pyrophosphatase from Mycobacterium tuberculosis. Journal of structural biology, 192(1), 76-87. https://doi.org/10.1016/j.jsb.2015.08.010

20. Beg, A., Khan, F. I., Lobb, K. A., Islam, A., Ahmad, F., \& Hassan, M. I. (2019). High throughput screening, docking, and molecular dynamics studies to identify potential inhibitors of human calcium/calmodulin-dependent protein kinase IV. Journal of biomolecular structure \& dynamics, 37(8), 2179-2192. https://doi.org/10.1080/07391102.2018.1479310

21. Meena, L. S., Chopra, P., Bedwal, R. S., \& Singh, Y. Cloning and characterization of GTP-binding proteins of Mycobacterium tuberculosis $\mathrm{H}_{37} \mathrm{Rv}$. Enzyme and microbial technology 42(2) (2008) 138144.

22. Meena, L. S., \& Rajni (2011) Cloning and characterization of engA, a GTP-binding protein from Mycobacterium tuberculosis $\mathrm{H}_{37}$ Biologicals: 39(2) 94-99.

23. Gast, K., Damaschun, G., Misselwitz, R., \& Zirwer, D. (1992) Application of dynamic light scattering to studies of protein folding kinetics. European biophysics Journal : EBJ 21(5) 357-362.

24. Yang, J. T., Wu, C. S., \& Martinez, H. M. (1986) Calculation of protein conformation from circular dichroism. Methods in enzymology 130.208-269. https://doi.org/10.1016/0076-6879(86)30013-2.

25. Pierce, M. M., Raman, C. S., \& Nall, B. T. (1999) Isothermal titration calorimetry of protein-protein interactions. Methods (San Diego, Calif.) 19(2) 213-221.

26. Sharma, K., Gupta, M., Krupa, A., Srinivasan, N., \& Singh, Y. (2006) EmbR, a regulatory protein with ATPase activity, is a substrate of multiple serine/threonine kinases and phosphatase in 
Mycobacterium tuberculosis. FEBS Journal 273(12) 2711-2721.

27. Shivangi, Beg, M.A., Meena, L.S. (2018) Insights of Rv2921c (Ftsy) Gene of Mycobacterium tuberculosis $\mathrm{H}_{37} \mathrm{Rv}$ To Prove Its Significance by Computational Approach. Biomed J Sci \& Tech Res 12(2)- BJSTR. MS.ID.002231. DOI: 10.26717/ BJSTR.2018.12.002231.

28. Beg M.A., Shivangi, Athar, F., Meena, L.S., (2018) Structural and Functional Annotation of Rv1514c Gene of Mycobacterium tuberculosis $\mathrm{H}_{37}$ Rv As Glycosyl Transferases. J Adv Res Biotech 3(2):1-9.

29. Beg M.A., Shivangi, Sonu CT, Meena, L.S. (2019) Systematical Analysis to Assist the Significance of Rv1907c Gene with the Pathogenic Potentials of Mycobacterium tuberculosis $\mathrm{H}_{37} \mathrm{~J}$ Biotechnol Biomater 8: 286. doi: 10.4172/2155-952X.1000286. 0332

30. Beg M.A., Shivangi, Sonu CT, Meena, L.S. (2018) Structural prediction and mutational analysis of Rv3906c gene of Mycobacterium tuberculosis $\mathrm{H}_{37} \mathrm{Rv}$ to determine its essentiality in survival. doi: 10.1155/2018/6152014. eCollection 2018.

31. Konc, J., Miller, B. T., Stular, T., Lesnik, S., Woodcock, H. L., Brooks, B. R., and Janezic, D. (2015) ProBiS-CHARMMing: Web Interface for Prediction and Optimization of Ligands in Protein Binding Sites. J. Chem. Inf. Model., 55, 2308-2314.

32. Zhou, H., \& Skolnick, J. (2013). FINDSITE(comb): a threading/structure-based, proteomic-scale virtual ligand screening approach. Journal of chemical information and modeling, 53(1), 230-240. https://doi.org/10.1021/ci300510n

33. Buchan, D., \& Jones, D. T. (2019). The PSIPRED Protein Analysis Workbench: 20 years on. Nucleic acids research, 47(W1), W402-W407. https://doi.org/10.1093/nar/gkz297

34. Shivangi, Beg M.A., Meena, L.S. (2019) Mutational effects on structural stability of SRP pathway dependent cotranslational protein ftsY of Mycobacterium tuberculosis $\mathrm{H}_{37}$ Gene Reports. 15100395 .

35. Pires, D. E., Ascher, D. B., \& Blundell, T. L. (2014). DUET: a server for predicting effects of mutations on protein stability using an integrated computational approach. Nucleic acids research, 42(Web Server issue), W314-W319. https://doi.org/10.1093/nar/gku411

36. Gautam, P., Shivangi, \& Meena, L. S. (2020). Revelation of point mutations effect in Mycobacterium tuberculosis MfpA protein that involved in mycobacterial DNA supercoiling and fluoroquinolone resistance. Biotechnology and applied biochemistry, 10.1002/bab.2058. Advance online publication. https://doi.org/10.1002/bab.2058

37. Mohammad, T., Mathur, Y., \& Hassan, M. I. (2020). InstaDock: A single-click graphical user interface for molecular docking-based virtual high-throughput screening. Briefings in bioinformatics, bbaa279. Advance online publication. https://doi.org/10.1093/bib/bbaa279

38. Hassan, N. M., Alhossary, A. A., Mu, Y., \& Kwoh, C. K. (2017). Protein-Ligand Blind Docking Using QuickVina-W With Inter-Process Spatio-Temporal Integration. Scientific reports, 7(1), 15451. https://doi.org/10.1038/s41598-017-15571-7 
39. O'Boyle, N. M., Banck, M., James, C. A., Morley, C., Vandermeersch, T., \& Hutchison, G. R. (2011). Open Babel: An open chemical toolbox. Journal of cheminformatics, 3, 33. https://doi.org/10.1186/17582946-3-33

40. Shivangi, \& Meena, L. S. (2020). Calcium ATPase signaling: A must include mechanism in the Radar of therapeutics development against Tuberculosis. Biotechnology and applied biochemistry, 10.1002/bab.2038. Advance online publication. https://doi.org/10.1002/bab.2038Shivangi, \& Meena, L.S. (2018) A Novel Approach in Treatment of Tuberculosis by Targeting Drugs to Infected Macrophages Using Biodegradable Nanoparticles. Appl Biochem Biotechnol. 185(3):815-821.

42. Yang, H., \& Lu, S. (2020). COVID-19 and Tuberculosis. Journal of translational internal medicine, 8(2), 59-65. https://doi.org/10.2478/jtim-2020-0010

43. Shivangi, Kevlani, N., \& Meena, L.S. (2020) Distinctive features of Microvesicles as a transporter of GTP and iron to empower pathogenesis of Mycobacterium tuberculosis $\mathrm{H}_{37}$ Emerg Infect Dis Diag J: EIDDJ-100009.

44. Shivangi \& Meena, L.S. (2019) To target the PI3-Kinase pathway of Mycobacterium tuberculosis $\mathrm{H}_{37} \mathrm{Rv}$ phagosome by heavy metal ions. 37. Res Rev J Microbiol Biotechnol 8, 3.

45. Zhou, L., Ma, C., Xiao, T., Li, M., Liu, H., Zhao, X., Wan, K., \& Wang, R. (2019). A New Single Gene Differential Biomarker for Mycobacterium tuberculosis Complex and Non-tuberculosis Mycobacteria. Frontiers in microbiology, 10, 1887. https://doi.org/10.3389/fmicb.2019.01887

46. Verma, H., Shivangi, Meena, L. S. (2018) Delivery of antituberculosis drugs to Mycobacterium tuberculosis $\mathrm{H}_{37} \mathrm{Rv}$ infected macrophages via polylactide-co-glycolide (PLGA) nanoparticles. Int $J$ Mol Biol: Open Access, 3:5.

47. Tanwar, P., Shivangi, Meena, L.S. (2019) Cholesterol Metabolism: As a Promising Target Candidate for Tuberculosis Treatment by Nanomedicine. J Nanomater Mol Nanotechnol 8:4.

48. Pratt, A. C., Dewage, S. W., Pang, A. H., Biswas, T., Barnard-Britson, S., Cisneros, G. A., \& Tsodikov, O. V. (2015). Structural and computational dissection of the catalytic mechanism of the inorganic pyrophosphatase from Mycobacterium tuberculosis. Journal of structural biology, 192(1), 76-87. https://doi.org/10.1016/j.jsb.2015.08.010

49. Pang, A. H., Garzan, A., Larsen, M. J., McQuade, T. J., Garneau-Tsodikova, S., \& Tsodikov, O. V. (2016). Discovery of Allosteric and Selective Inhibitors of Inorganic Pyrophosphatase from Mycobacterium tuberculosis. ACS chemical biology, 11(11), 3084-3092.

https://doi.org/10.1021/acschembio.6b00510

50. Giraud-Gatineau, A., Coya, J. M., Maure, A., Biton, A., Thomson, M., Bernard, E. M., Marrec, J., Gutierrez, M. G., Larrouy-Maumus, G., Brosch, R., Gicquel, B., \& Tailleux, L. (2020). The antibiotic bedaquiline activates host macrophage innate immune resistance to bacterial infection. eLife, 9 , e55692. https://doi.org/10.7554/eLife.55692

51. Bharat, A., Blanchard, J. E., \& Brown, E. D. (2013). A high-throughput screen of the GTPase activity of Escherichia coli EngA to find an inhibitor of bacterial ribosome biogenesis. Journal of biomolecular 
screening, 18(7), 830-836. https://doi.org/10.1177/1087057113486001

52. Meena, L.S., \& Rajni. (2010) Survival mechanisms of pathogenic Mycobacterium tuberculosis $\mathrm{H}_{37} \mathrm{Rv}$. FEBS J277 (11): 2416-2427. doi: 10.1111/j.1742-4658.2010.07666.x.

53. , \& Meena, L.S. (2010) Guanosine triphosphatases as novel therapeutic targets in tuberculosis. Inter. J. Infect. Disease. 14: e682-e687.

54. , Ekka M.K., \& Meena, L.S. (2021) Essential Biochemical, Biophysical and computational inputs on efficient functioning of Mycobacteriumtuberculosis $\mathrm{H}_{37} \mathrm{Rv}$ Fts Y. Inter J Biol Macromolecules, 171; 5973. https://doi.org/10.1016/j.ijbiomac.2020.12.182.

\section{Tables}

Table 1: Comparison of mutations by EaseMM, Provean and I Mutant 3.0 


\begin{tabular}{|c|c|c|c|c|}
\hline S.No. & Residue & Ease MM & Provean & I Mutant 3.0 \\
\hline 1. & W102G & -4.9260 & $-4.270 /$ Deleterious & -1.92 \\
\hline 2. & V150G & -4.1111 & $-6.245 /$ Deleterious & -1.76 \\
\hline 3. & F44G & -4.4003 & $-7.503 /$ Deleterious & -2.12 \\
\hline 4. & I119G & -4.5212 & $-7.769 /$ Deleterious & -2.55 \\
\hline 5. & L93F & -4.4532 & $-3.937 /$ Deleterious & -2.68 \\
\hline 6. & F3G & -4.4500 & $-7.769 /$ Deleterious & -2.21 \\
\hline 7. & $\mathrm{~F} 122 \mathrm{G}$ & -4.6320 & $-8.969 /$ Deleterious & -2.43 \\
\hline 8. & I108G & -4.2590 & $-6.596 /$ Deleterious & -2.50 \\
\hline 9. & L32G & -4.1747 & $-7.911 /$ Deleterious & -3.34 \\
\hline 10. & M82G & -4.1845 & -7.992/Deleterious & -1.80 \\
\hline 11. & Y17G & -4.3607 & $-9.889 /$ Deleterious & -2.28 \\
\hline 12. & L59G & -4.5909 & $-7.579 /$ Deleterious & -2.54 \\
\hline 13. & V5G & -4.1883 & $-6.260 /$ Deleterious & -2.17 \\
\hline 14. & V26G & -4.0069 & $-6.759 /$ Deleterious & -2.80 \\
\hline 15. & I7G & -4.7302 & $-7.507 /$ Deleterious & -2.81 \\
\hline 16. & W140D & -4.0817 & $-14.786 /$ Deleterious & -1.43 \\
\hline 17. & W140G & -4.8978 & $-12.954 /$ Deleterious & -1.69 \\
\hline 18. & W140A & -4.0414 & $-13.953 /$ Deleterious & -1.20 \\
\hline 19. & F80G & -4.730 & $-8.402 /$ Deleterious & -2.38 \\
\hline 20. & W140S & -4.4166 & $-13.853 /$ Deleterious & -1.33 \\
\hline 21. & L49G & -4.0531 & -7.906/Deleterious & -2.48 \\
\hline 22. & L56G & -4.4514 & -7.704/Deleterious & -2.34 \\
\hline 23. & I9G & -4.6410 & -7.839/Deleterious & -2.89 \\
\hline 24. & V60G & -4.1519 & $-6.856 /$ Deleterious & -2.21 \\
\hline 25. & V19G & -4.0048 & $-6.504 /$ Deleterious & -2.60 \\
\hline 26. & V92G & -4.0486 & $-6.505 /$ Deleterious & -2.35 \\
\hline 27. & L28G & -4.5469 & $-7.911 /$ Deleterious & -3.51 \\
\hline 28. & L61G & -4.2705 & $-7.428 /$ Deleterious & -2.59 \\
\hline
\end{tabular}




\begin{tabular}{|lllll|} 
29. & Y126E & -4.7996 & $-8.991 /$ Deleterious & -0.85 \\
30. & F123G & -4.4530 & $-8.969 /$ Deleterious & -2.48 \\
\hline
\end{tabular}

Table 2: Impact of mutations at the active site residues

\begin{tabular}{|lllll|}
\hline & EASE MM & PROVEAN & I mutant & DynaMut \\
\hline E8G & -2.3658 & -6.922 & -2.13 & -1.004 \\
\hline K16G & -1.6227 & -6.922 & -2.44 & -1.700 \\
\hline R30G & -3.1748 & -6.922 & -1.58 & -0.877 \\
\hline Y42G & -3.9978 & -9.889 & -1.10 & -3.295 \\
\hline Y126G & -4.7996 & -9.990 & -1.13 & -2.079 \\
\hline
\end{tabular}

Table 3: Active site mutations at different temperatures

\begin{tabular}{|lllllll|}
\hline $\begin{array}{r}\text { Temp } \\
\text { Mutation }\end{array}$ & $\mathbf{4}^{\mathbf{0}} \mathbf{C}$ & $\mathbf{1 6}^{\circ} \mathbf{C}$ & $\mathbf{2 5}^{\circ} \mathbf{C}$ & $\mathbf{3 7}^{\circ} \mathbf{C}$ & $\mathbf{4 2}^{\circ} \mathbf{C}$ & $\mathbf{6 0}^{\circ} \mathbf{C}$ \\
\hline Y126G & -2.28 & -2.20 & -2.13 & -2.04 & -1.97 & -1.76 \\
\hline Y42G & -2.60 & -2.52 & -2.44 & -2.32 & -2.26 & -2.03 \\
\hline R30G & -1.76 & -1.66 & -1.58 & -1.46 & -1.40 & -1.19 \\
\hline E8G & -1.33 & -1.20 & -1.10 & -0.94 & -0.88 & -0.77 \\
\hline K16G & -1.31 & -1.21 & -1.13 & -1.02 & -0.97 & -0.89 \\
\hline
\end{tabular}

Table 4: Active site mutations at different pH

\begin{tabular}{|llllll|}
\hline \multicolumn{1}{|c}{$\mathbf{p H}$} & $\mathbf{3}$ & $\mathbf{5}$ & $\mathbf{7}$ & $\mathbf{1 0}$ & $\mathbf{1 3}$ \\
Mutation & & & & & \\
\hline Y126G & -2.13 & -2.14 & -2.13 & -2.06 & -2.08 \\
\hline Y42G & -2.46 & -2.47 & -2.44 & -2.35 & -2.20 \\
\hline R30G & -1.51 & -1.56 & -1.58 & -1.58 & -1.53 \\
\hline E8G & -1.05 & -1.08 & -1.10 & -1.09 & -1.05 \\
\hline K16G & -1.11 & -1.13 & -1.13 & -1.12 & -1.07 \\
\hline
\end{tabular}

Table 5: Phosphorylation site prediction 


\begin{tabular}{|lllll|}
\hline S. No. & Residue & Context & Score & Kinase \\
\hline 1. & Y2 & MYCXXA & 0.400 & INSR \\
\hline 2. & T8 & ACTERIX & 0.586 & unsp \\
\hline 3. & T14 & RIXMTXXER & 0.734 & Unsp \\
\hline 4. & T14 & RIXMTXXER & 0.541 & CKII \\
\hline 5. & T56 & VDHETGRVR & 0.795 & Unsp \\
\hline 6. & T56 & VDHETGRVR & 0.705 & PKC \\
\hline 7. & Y64 & RLDRYLYTP & 0.618 & unsp \\
\hline 8. & T73 & MAYPTDYGF & 0.500 & PKG \\
\hline 9. & Y75 & YPTDYGFIE & 0.683 & Unsp \\
\hline 10. & T81 & FIEDTLGDD & 0.801 & Unsp \\
\hline 11. & T81 & FIEDTLGDD & 0.519 & CKI \\
\hline 12. & Y159 & FFVHYKDLE & 0.511 & unsp \\
\hline 13. & S186 & EVQRSVERF & 0.995 & unsp \\
\hline 14. & S186 & EVQRSVERF & 0.995 & unsp \\
\hline 15. & T194 & FKAGTH & 0.660 & PKC \\
\hline
\end{tabular}

Table 6: Epitope prediction 


\begin{tabular}{|llll|}
\hline S. No. & Sequence & Start Position & Score \\
\hline $\mathbf{1}$ & FRMVDEHGGDDKVLCV & 80 & 0.93 \\
\hline $\mathbf{2}$ & GVLVAARPVGMFRMVD & 69 & 0.90 \\
\hline $\mathbf{3}$ & DVTIEIPKGQRNKYEV & 4 & 0.88 \\
\hline $\mathbf{4}$ & FFVHYKDLEPGKFVKA & 122 & 0.88 \\
\hline $\mathbf{4}$ & GCVPAGDPRWDHVQDI & 93 & 0.86 \\
\hline $\mathbf{4}$ & NKYEVDHETGRVRLDR & 15 & 0.86 \\
\hline $\mathbf{5}$ & DHVQDIGDVPAFELDA & 103 & 0.86 \\
\hline $\mathbf{6}$ & YGFIEDTLGDDGDPLD & 42 & 0.84 \\
\hline $\mathbf{7}$ & YTPMAYPTDYGFIEDT & 33 & 0.83 \\
\hline $\mathbf{8}$ & AADWVDRAEAEAEVQR & 137 & 0.80 \\
\hline $\mathbf{9}$ & AFELDAIKHFFVHYKD & 113 & 0.77 \\
\hline $\mathbf{1 0}$ & LGDDGDPLDALVLLPQ & 49 & 0.76 \\
\hline $\mathbf{1 1}$ & LVLLPQPVFPGVLVAA & 59 & 0.72 \\
\hline $\mathbf{1 2}$ & EAEVQRSVERFKAGTH & 147 & 0.71 \\
\hline
\end{tabular}

Table 7: Binding affinity of nucleotides, GTPase inhibitors and natural inhibitors 


\begin{tabular}{|c|c|c|c|c|}
\hline S.No & Name of the ligand & $\begin{array}{l}\text { Binding Free Energy } \\
\text { (kcal/mol) }\end{array}$ & pKi & $\begin{array}{l}\text { Ligand Efficiency } \\
\text { (kcal/mol/non-H atom) }\end{array}$ \\
\hline \multicolumn{5}{|c|}{ NTDs } \\
\hline 1 & ATP & -7.5 & 5.5 & 0.1562 \\
\hline 2 & ADP & -7.3 & 5.35 & 0.1698 \\
\hline 3 & GTP & -7.5 & 5.5 & 0.1531 \\
\hline 4 & GDP & -7.9 & 5.79 & 0.1881 \\
\hline 5 & $\mathrm{CDP}$ & -7.1 & 5.21 & 0.1775 \\
\hline 6 & CTP & -6.9 & 5.06 & 0.1468 \\
\hline 7 & UDP & -7.6 & 5.57 & 0.2 \\
\hline 8 & UTP & -6.7 & 4.91 & 0.1489 \\
\hline \multicolumn{5}{|c|}{ GTPase Inhibitors } \\
\hline 1 & mac0182344 & -8.7 & 6.38 & 0.1403 \\
\hline 2 & NAV_2729 & -8.5 & 6.23 & 0.2125 \\
\hline 3 & br_gtp & -8.5 & 6.23 & 0.1977 \\
\hline 4 & $\mathrm{ml} 141$ & -7.7 & 5.65 & 0.2081 \\
\hline 5 & Rhosin-Hcl & -7.7 & 5.65 & 0.2139 \\
\hline 6 & nsc_23766 & -7.6 & 5.57 & 0.1727 \\
\hline 7 & CID_1067700 & -7.4 & 5.43 & 0.2114 \\
\hline 8 & ITX3 & -7.3 & 5.35 & 0.2355 \\
\hline 9 & EHT1864 & -6.9 & 5.06 & 0.1438 \\
\hline 10 & berberine & -6.8 & 4.99 & 0.2345 \\
\hline 11 & Salirasib & -6.8 & 4.99 & 0.1789 \\
\hline 12 & mac0174809 & -6.7 & 4.91 & 0.1136 \\
\hline 13 & mac0182099 & -6.7 & 4.91 & 0.1031 \\
\hline 14 & ccg_50014 & -6.6 & 4.84 & 0.2444 \\
\hline 15 & nexinhib20 & -6.3 & 4.62 & 0.2172 \\
\hline 16 & mac0080023 & -6.1 & 4.47 & 0.2259 \\
\hline
\end{tabular}




\begin{tabular}{|lrlll|}
\hline \multicolumn{2}{|l}{ Top ten Natural Inhibitors } \\
1 & ZINC000003780340 & -9.7 & 7.11 & 0.2109 \\
\hline 2 & ZINC000003979028 & -9.5 & 6.97 & 0.1827 \\
\hline 3 & ZINC000003870413 & -9.4 & 6.89 & 0.2 \\
\hline 4 & ZINC000003870412 & -9.2 & 6.75 & 0.1957 \\
\hline 5 & ZINC000150338758 & -9.2 & 6.75 & 0.1108 \\
\hline 6 & ZINC000070450948 & -9.1 & 6.67 & 0.175 \\
\hline 7 & ZINC000150338754 & -9.1 & 6.67 & 0.1096 \\
\hline 8 & ZINC000095098891 & -9 & 6.6 & 0.2368 \\
\hline 9 & ZINC000000119985 & -9 & 6.6 & 0.3103 \\
\hline 10 & ZINC000005085286 & -8.9 & 6.53 & 0.1561 \\
\hline
\end{tabular}

Table 8: Lipinski's Rule of 5 on natural inhibitors

\begin{tabular}{|llllllll|}
\hline Name of the ligand & Binding Free Energy $(\mathrm{kcal} / \mathrm{mol})$ & MW & RB & HA & HD & logP & Vio \\
& & $\mathbf{g} / \mathrm{mol}$ & & & & & \\
\hline ZINC000003780340 & -9.7 & 504.44 & 0 & 8 & 6 & 3.13 & 2 \\
\hline ZINC000003979028 & -9.5 & 458.37 & 4 & 11 & 8 & 1.83 & 2 \\
\hline ZINC000003870413 & -9.4 & 458.37 & 4 & 11 & 8 & 1.83 & 2 \\
\hline ZINC000003870412 & -9.2 & 458.37 & 4 & 11 & 8 & 1.53 & 2 \\
\hline ZINC000150338758 & -9.2 & 864.76 & 4 & 18 & 14 & 2.52 & 3 \\
\hline ZINC000070450948 & -9.1 & 564.54 & 6 & 9 & 2 & 4.78 & 1 \\
\hline ZINC000150338754 & -9.1 & 864.76 & 4 & 18 & 14 & 2.52 & 3 \\
\hline ZINC000095098891 & -9 & 456.70 & 1 & 3 & 2 & 3.90 & 1 \\
\hline ZINC000000119985 & -9 & 290.27 & 1 & 6 & 5 & 1.36 & 0 \\
\hline ZINC000005085286 & -8.9 & 578.52 & 3 & 12 & 10 & 2.23 & 3 \\
\hline
\end{tabular}

Table 9: PASS online prediction of properties of natural compound 


\begin{tabular}{|llll|}
\hline Name of the ligand & $\mathbf{P a}$ & $\mathbf{P i}$ & Activity \\
\hline ZINC000003780340 & 0,912 & 0,009 & CYP2C12 substrate \\
\hline ZINC000003979028 & 0,969 & 0,002 & HMOX1 expression enhancer \\
\hline ZINC000003870413 & 0,969 & 0,002 & HMOX1 expression enhancer \\
\hline ZINC000003870412 & 0,969 & 0,002 & HMOX1 expression enhancer \\
\hline ZINC000150338758 & 0,968 & 0,002 & Membrane integrity agonist \\
\hline ZINC000070450948 & 0,961 & 0,001 & CYP1A inducer \\
\hline ZINC000150338754 & 0,968 & 0,002 & Membrane integrity agonist \\
\hline ZINC000095098891 & 0,984 & 0,002 & Caspase 3 stimulant \\
\hline ZINC000000119985 & 0,983 & 0,001 & Membrane integrity agonist \\
\hline ZINC000005085286 & 0,968 & 0,002 & Membrane integrity agonist \\
\hline
\end{tabular}

Table 10: Absorption and Toxicity prediction

\begin{tabular}{|llllll|}
\hline Name of the ligand & GI abs. & BBB & $\begin{array}{l}\text { Log Kp } \\
(\mathbf{c m} / \mathbf{s})\end{array}$ & AMES toxicity (A.T) & Carcinogens \\
\hline ZINC000003780340 & Low & No & -4.48 & A.T & Non-C \\
\hline ZINC000003979028 & Low & No & -8.27 & Non-A.T & Non-C \\
\hline ZINC000003870413 & Low & No & -8.27 & Non-A.T & Non-C \\
\hline ZINC000003870412 & Low & No & -8.27 & Non-A.T & Non-C \\
\hline ZINC000150338758 & Low & No & -9.21 & Non-A.T & Non-C \\
\hline ZINC000070450948 & Low & No & -5.61 & Non-A.T & Non-C \\
\hline ZINC000150338754 & Low & No & -9.21 & Non-A.T & Non-C \\
\hline ZINC000095098891 & Low & No & -3.77 & Non-A.T & Non-C \\
\hline ZINC000000119985 & High & No & -7.82 & Non-A.T & Non-C \\
\hline ZINC000005085286 & Low & No & -9.30 & Non-A.T & Non-C \\
\hline
\end{tabular}

\section{Figures}


(a.)

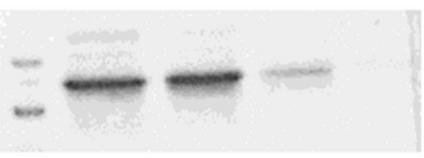

(b.)
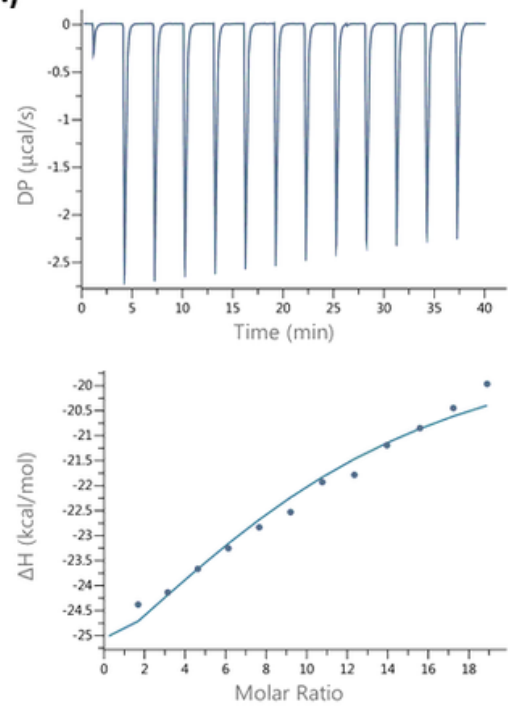

(c.)

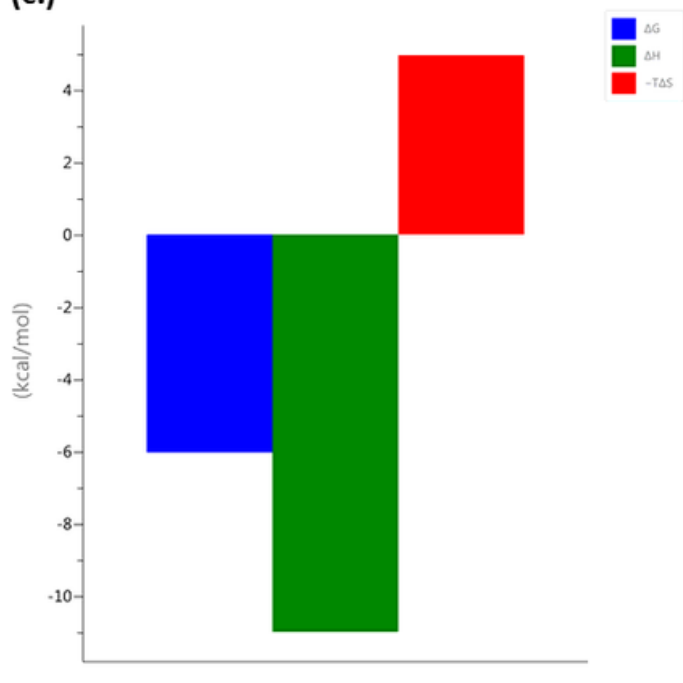

\section{Figure 1}

Protein purification and interaction analysis: (a.) Mt-ppa protein was purified with his tag at 20Kda. (b.) Isothermal calorimetry: ITC was performed to check the interaction of Mt-ppa with GTP. The protein interacted with the higher amounts of GTP. (c.) Thermal graph: the reaction showed spontaneous reaction with negative $\Delta \mathrm{G}, \Delta \mathrm{H}$ and positive $\mathrm{T} \Delta \mathrm{S}$. 
(a.)

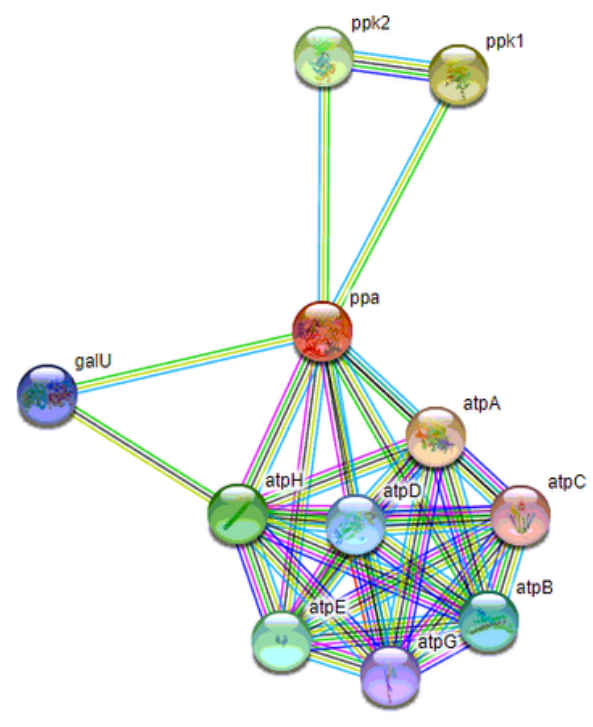

(b.)

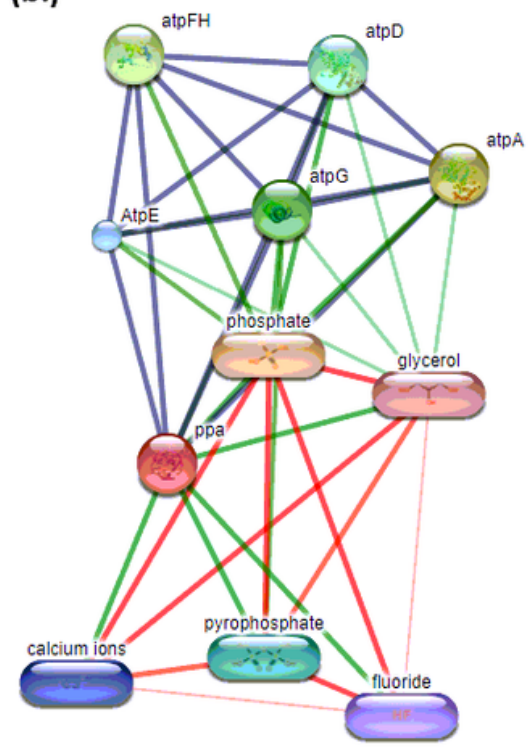

\section{Figure 2}

Interaction analysis: (a.) Protein-protein interaction: Protein-protein interaction was checked by STRING server that showed Mt-ppa interaction with ATP family protein and ppk1 and ppk 2 with score greater than 0.9. (b.) Protein-compound interaction: Protein compound interaction was checked by STITCH database which showed its binding with pyrophosphate, calcium, fluoride and glycerol with scores ranges in 0.8-1.0. 


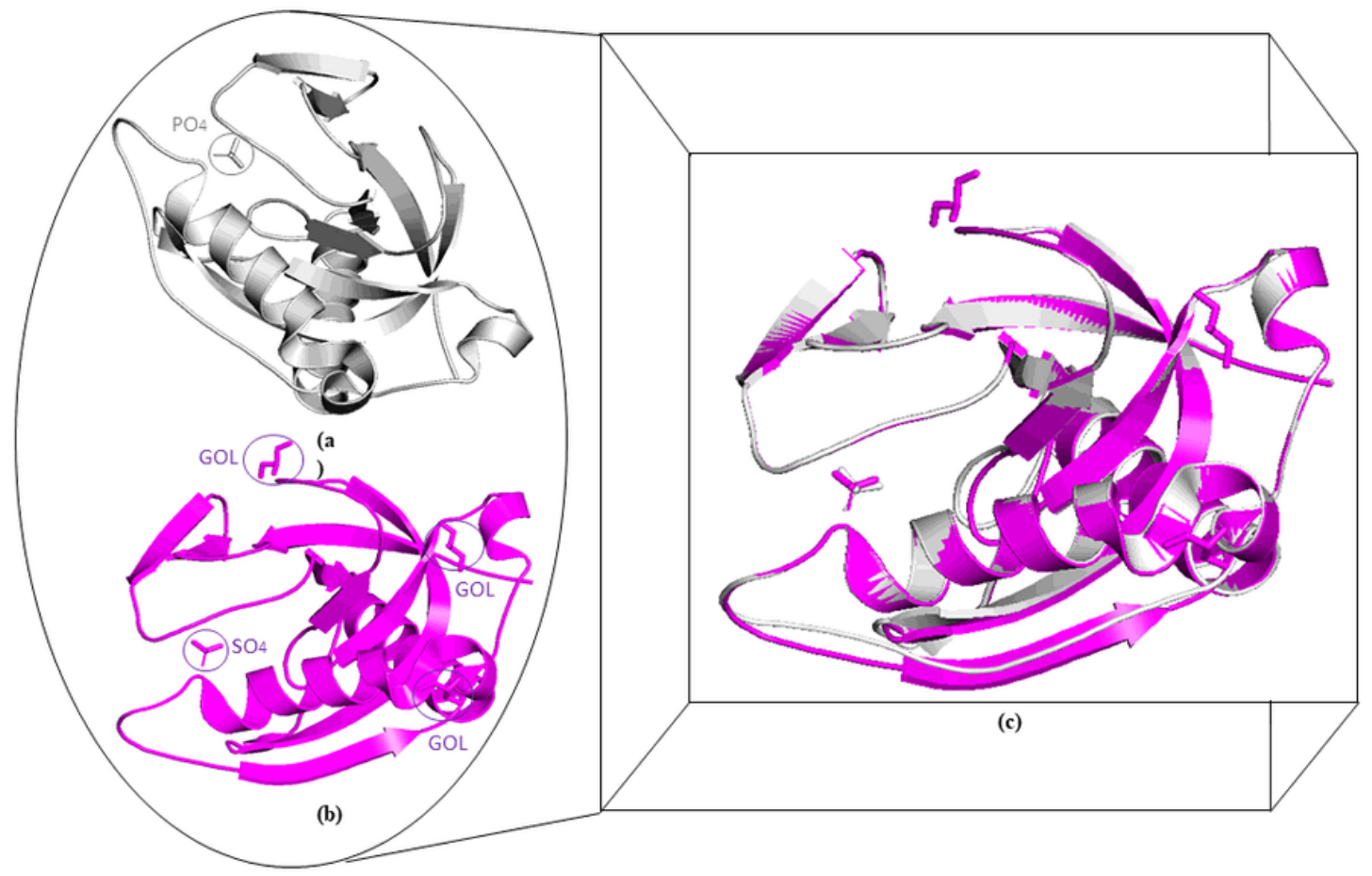

Figure 3

Comparison of 1WCF and 1SXV: Most of the residues of both structures are aligned between 1WCF and 1SXV.
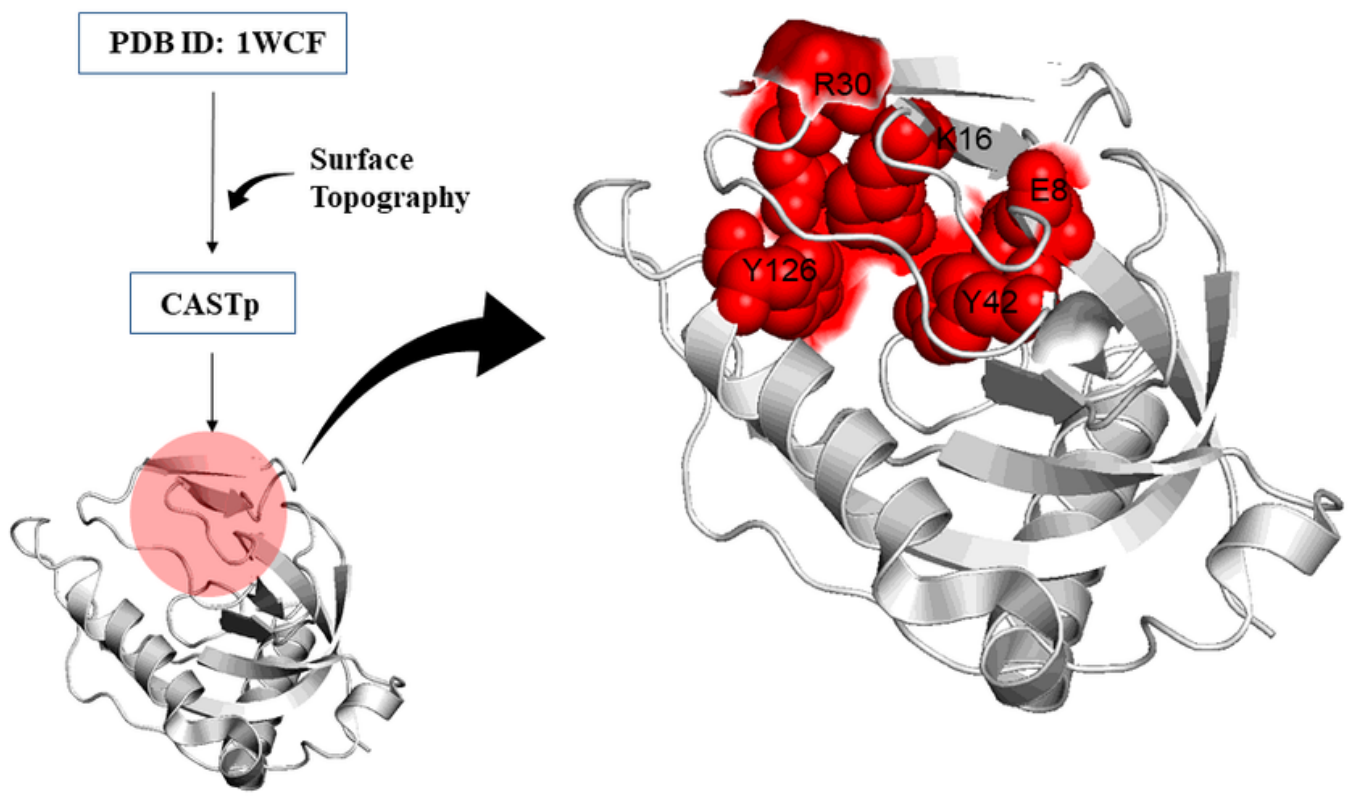
Figure 4

Active site residue prediction: Active site was predicted by CASTp server and R30, K16, Y12, E8 and Y42 are the residues that are present in the active site.
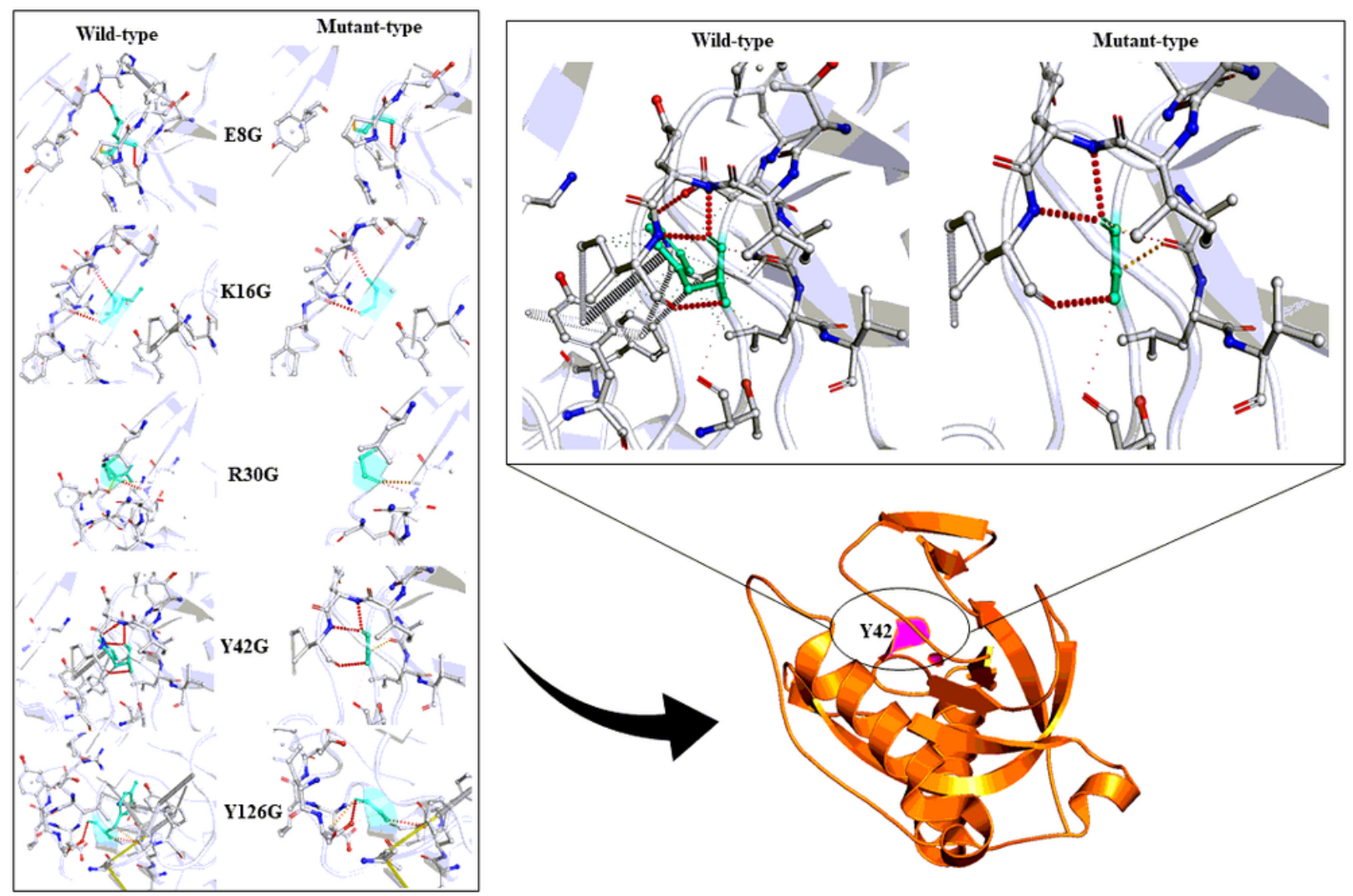

\section{Figure 5}

Structure based mutation: Structural based mutation analysis was done on active site residues. All mutations showed decrease in protein dynamic stability due to disruption of interatomic interactions. The highest decreased stability was due to Y42G substitution which is showed in the separate diagram. 
(a.)

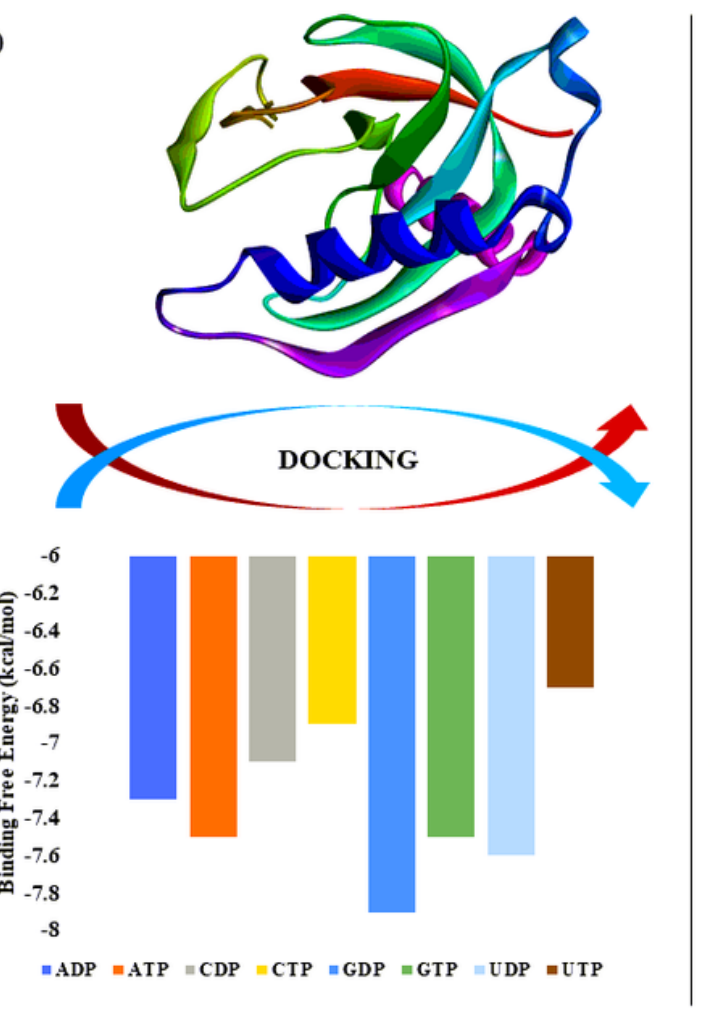

(b.)

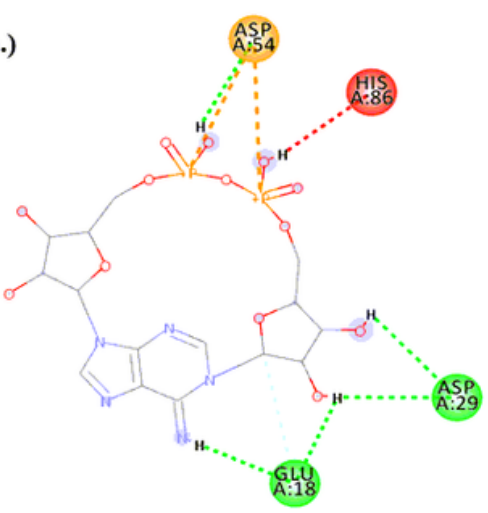

Mt-ppa_ADP

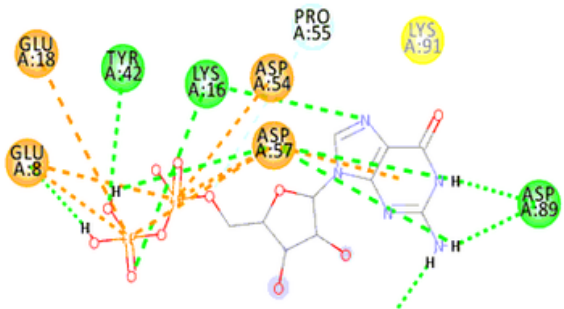

A. A 55

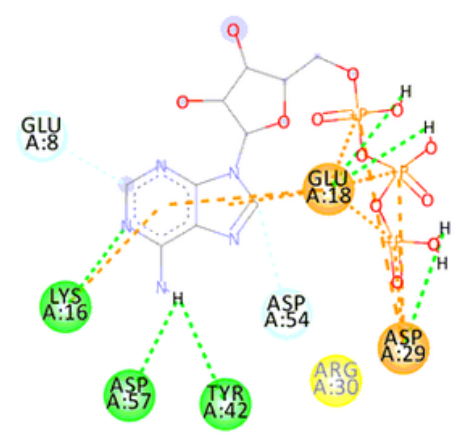

Mt-ppa_ATP

AH:Ls

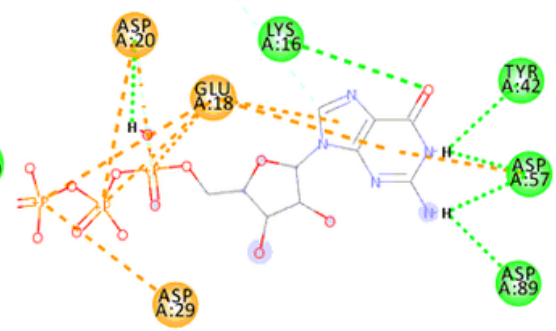

Mt-ppa_GTP

\section{Figure 6}

Docking of Mt-ppa with nucleotides: (a.) Binding energy graph: Mt-ppa was docked with all nucleotides in INSTADOCK server and it was found that Mt-ppa docked with all nucleotides in the order of $G D P>U D P>A T P>G T P>A D P>C D P>C T P>U T P$. (b.) Interaction analysis: Interaction analysis between Mt-ppa and two major signaling molecule (ATP and GTP) and their dinucleotides was done by pymol visualization server. There was extensive hydrogen bonding was seen in all interactions. 


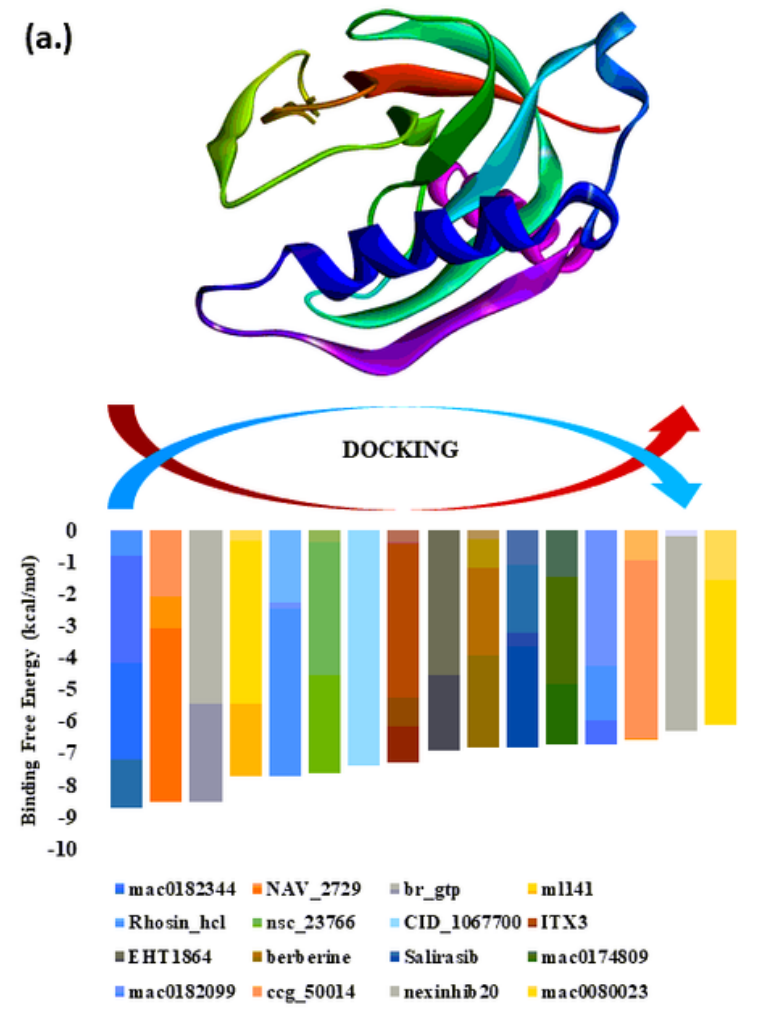

(b.)
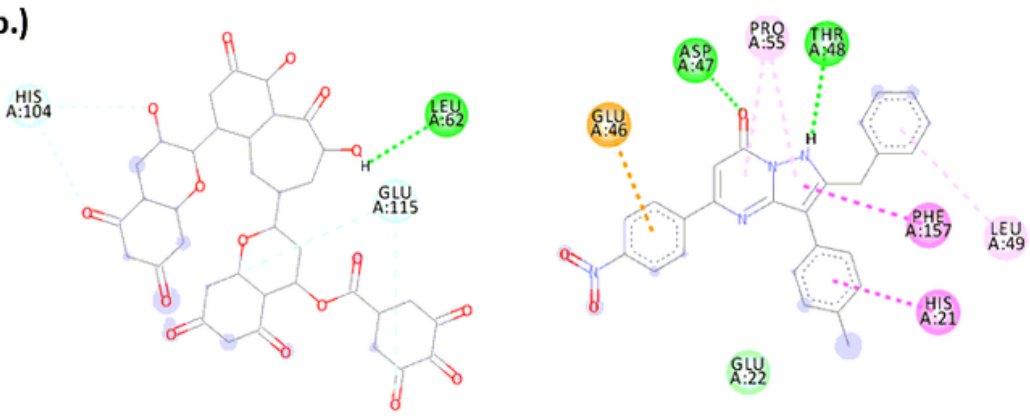

Mt-ppa_Mac0182344

Mt-ppa_NAV2729
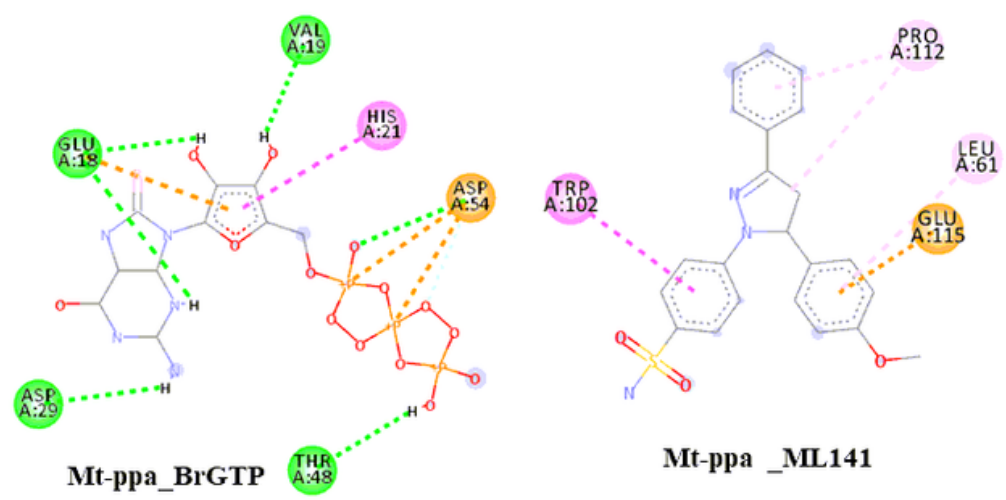

\section{Figure 7}

Docking of Mt-ppa with GTPase inhibitors: (a.) Binding energy graph: Mt-ppa was docked with known GTPase inhibitors in INSTADOCK server and it was found that Mt-ppa was significantly docked with all inhibitors. (b.) Interaction analysis: Interaction analysis between Mt-ppa and top hits of inhibitors was checked. Mac0182344, NAV2729, Br GTP and ML141 were the top hits of inhibitors that were indulged in the interaction by hydrogen, alkyl and van der waals interaction. 

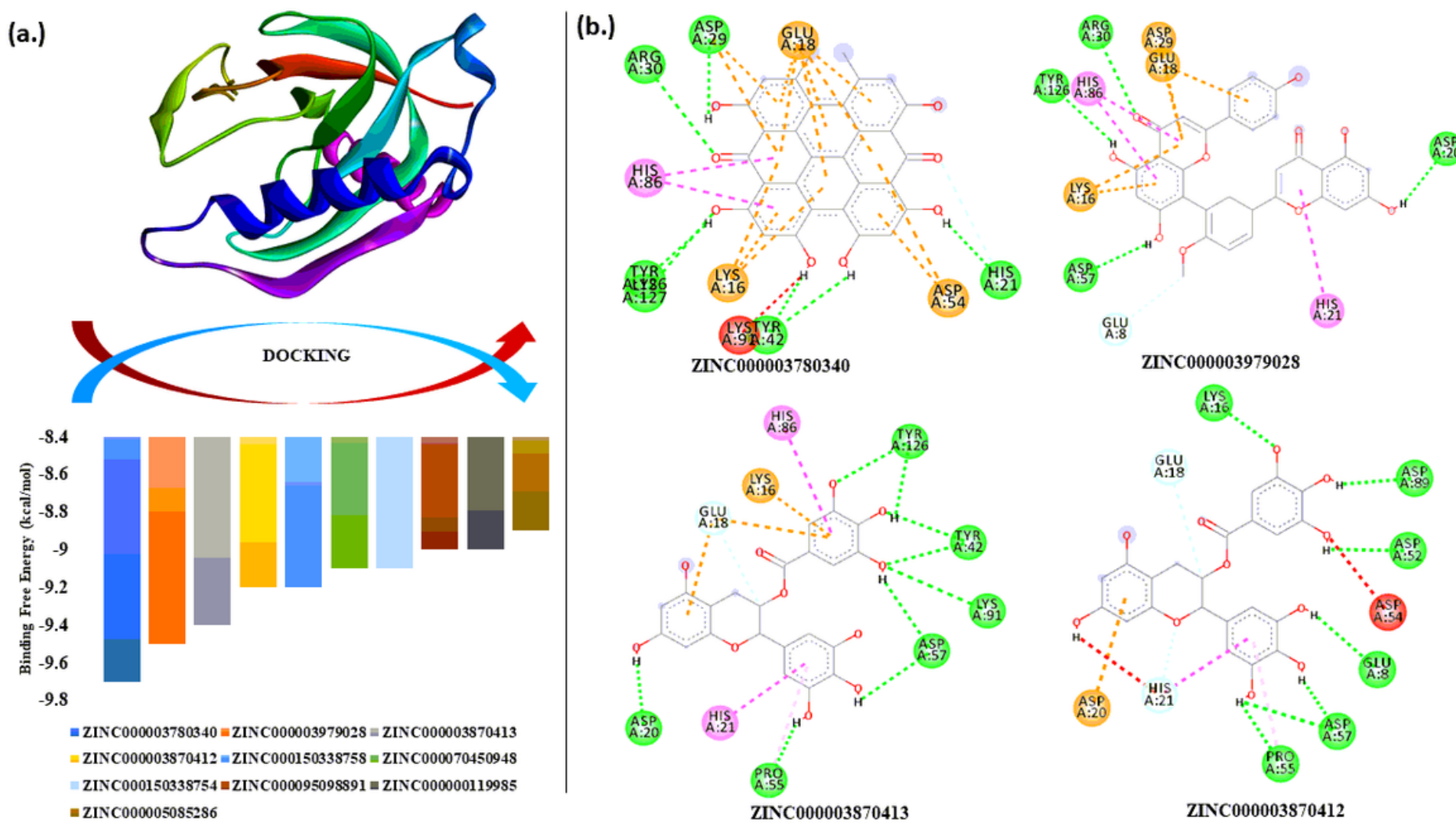

\section{Figure 8}

Docking of Mt-ppa with HITs: (a.) Binding energy graph: Mt-ppa was docked with known HITs subset of ZINC database in INSTADOCK server and it was found that Mt-ppa was significantly docked with all HIT compounds and top hits were further checked for interaction analysis. (b.) Interaction analysis: Interaction analysis between Mt-ppa and top hits of HIT compounds was checked. ZINC000003780340, ZINC000003979028, ZINC000003870413, ZINC000003870412 were the top hits of HIT compounds that were indulged in the interaction by hydrogen, alkyl and van der waals interaction. 